\title{
What effect does VOC sampling time have on derived $\mathrm{OH}$ reactivity?
}

\author{
Hannah Sonderfeld ${ }^{1}$, Iain R. White ${ }^{1}$, Iain C. A. Goodall ${ }^{1, a}$, James R. Hopkins ${ }^{2}$, Alastair C. Lewis ${ }^{2}$, Ralf Koppmann ${ }^{3}$, \\ and Paul S. Monks ${ }^{1}$ \\ ${ }^{1}$ Department of Chemistry, University of Leicester, Leicester, LE1 7RH, UK \\ ${ }^{2}$ National Centre for Atmospheric Science, University of York, York, YO10 5DD, UK \\ ${ }^{3}$ Institute for Atmospheric and Environmental Research, University of Wuppertal, 42119 Wuppertal, Germany \\ anow at: Faculty of Engineering and Science, Greenwich University, London, SE10 9LS, UK
}

Correspondence to: Paul S. Monks (p.s.monks@leicester.ac.uk)

Received: 27 November 2015 - Published in Atmos. Chem. Phys. Discuss.: 18 January 2016

Revised: 16 April 2016 - Accepted: 9 May 2016 - Published: 24 May 2016

\begin{abstract}
State-of-the-art techniques allow for rapid measurements of total $\mathrm{OH}$ reactivity. Unknown sinks of $\mathrm{OH}$ and oxidation processes in the atmosphere have been attributed to what has been termed "missing" $\mathrm{OH}$ reactivity. Often overlooked are the differences in timescales over which the diverse measurement techniques operate. Volatile organic compounds (VOCs) acting as sinks of $\mathrm{OH}$ are often measured by gas chromatography (GC) methods which provide lowfrequency measurements on a timescale of hours, while sampling times are generally only a few minutes. Here, the effect of the sampling time and thus the contribution of unmeasured VOC variability on $\mathrm{OH}$ reactivity is investigated. Measurements of VOC mixing ratios by proton transfer reaction time-of-flight mass spectrometry (PTR-ToF-MS) conducted during two field campaigns (ClearfLo and PARADE) in an urban and a semi-rural environment were used to calculate $\mathrm{OH}$ reactivity. VOCs were selected to represent variability for different compound classes. Data were averaged over different time intervals to simulate lower time resolutions and were then compared to the mean hourly $\mathrm{OH}$ reactivity. The results show deviations in the range of 1 to $25 \%$. The observed impact of VOC variability is found to be greater for the semi-rural site.

The selected compounds were scaled by the contribution of their compound class to the total $\mathrm{OH}$ reactivity from VOCs based on concurrent gas chromatography measurements conducted during the ClearfLo campaign. Prior to being scaled, the variable signal of aromatic compounds results in larger deviations in $\mathrm{OH}$ reactivity for short sampling intervals com-
\end{abstract}

pared to oxygenated VOCs (OVOCs). However, once scaled with their lower share during the ClearfLo campaign, this effect was reduced. No seasonal effect on the $\mathrm{OH}$ reactivity distribution across different VOCs was observed at the urban site.

\section{Introduction}

Atmospheric photochemistry produces a variety of radicals that exert a substantial influence on the ultimate composition of the atmosphere. The $\mathrm{OH}$ radical is the main oxidant in the atmosphere (Monks et al., 2009, and references therein). Its actual concentration is determined by the balance between its sources and sinks. While in many cases $\mathrm{OH}$ sources are well understood, $\mathrm{OH}$ sinks are manifold and not completely characterised. $\mathrm{OH}$ reactivity is a measure of the strength of the sinks for the $\mathrm{OH}$ radical. It can be derived from the reaction rates of the reactants $k_{\mathrm{OH}+X}$ and their concentrations [X] (Kovacs et al., 2003):

$$
\begin{aligned}
k_{\mathrm{OH}}= & \sum k_{\mathrm{OH}+\mathrm{VOC}_{i}}\left[\mathrm{VOC}_{i}\right]+k_{\mathrm{OH}+\mathrm{CO}}[\mathrm{CO}] \\
& +k_{\mathrm{OH}+\mathrm{NO}}[\mathrm{NO}]+k_{\mathrm{OH}+\mathrm{NO}_{2}}\left[\mathrm{NO}_{2}\right] \\
& +k_{\mathrm{OH}+\mathrm{SO}_{2}}\left[\mathrm{SO}_{2}\right]+\ldots
\end{aligned}
$$

In situ measurements of $\mathrm{OH}$ reactivity have provided new insights into $\mathrm{OH}$ loss chemistry and the oxidative ability of the atmosphere (e.g. Di Carlo et al., 2004; Edwards et al., 2013; Hofzumahaus et al., 2009; Whalley et al., 2011; 
Yoshino et al., 2006). There are a number of different techniques used for the direct measurement of $\mathrm{OH}$ reactivity. The total $\mathrm{OH}$ loss rate measurement technique (TOHLM) was one of the first techniques applied for determination of total $\mathrm{OH}$ reactivity based on a single measurement (Ingham et al., 2009; Ren et al., 2003a; Shirley et al., 2006). TOHLM is based on the measurement of the decay of artificially produced $\mathrm{OH}$ following the introduction of reactants into an ambient air sample within a flow tube. By varying the distance between the $\mathrm{OH}$ injection point and the detector, the reaction time changes and provides a series of relative decay rates (Kovacs et al., 2003; Kovacs and Brune, 2001). A similar approach is taken with the laser-induced pump and probe technique, whereby decay in $\mathrm{OH}$ is detected by timeresolved laser-induced fluorescence (Sadanaga et al., 2004). Another technique developed by Sinha et al. (2008), called the comparative reactivity method (CRM), is based on the measurement of a single reactant (most often pyrrole) which first reacts with $\mathrm{OH}$ under clean air conditions and then under competitive conditions with ambient air. The reaction takes place in a glass vessel and is most commonly probed by PTRMS. Recently, Nölscher et al. (2012b) presented a GC-PID for the detection of pyrrole for CRM.

These techniques enable comparison of directly measured $\mathrm{OH}$ reactivity to calculated $\mathrm{OH}$ reactivity using Eq. (1) based on measurements of individual compounds. The difference between the two is referred to as missing $\mathrm{OH}$ reactivity. Reasons for an under-prediction of $\mathrm{OH}$ reactivity maybe due to incomplete or inaccurate measurements of individual compounds (Di Carlo et al., 2004; Kim et al., 2011; Kovacs and Brune, 2001). Therefore, direct measurements of total $\mathrm{OH}$ reactivity can help to evaluate the completeness of measured VOC budgets (Dolgorouky et al., 2012; Mao et al., 2009; Mogensen et al., 2011).

In urban environments good agreement between measured and calculated $\mathrm{OH}$ reactivity has been found. For example, no significant missing $\mathrm{OH}$ reactivity was found in New York during summer (Ren et al., 2003b) and for both Paris under clean marine air conditions (Dolgorouky et al., 2012) and Tokyo (Yoshino et al., 2006) in the winter. Larger missing $\mathrm{OH}$ reactivity of up to $30 \%$ was found for all other seasons in Tokyo by Yoshino et al. (2006), presumably owing to secondary reaction products, including semi-volatile oxygenated compounds, from atmospheric oxidation of VOCs. A similar amount of missing $\mathrm{OH}$ reactivity was reported by Kovacs et al. (2003) for urban measurements in Nashville. They suggest that non-measured short-lived VOCs accounted for the missing reactivity. In Paris, a missing $\mathrm{OH}$ reactivity of up to $75 \%$ was found for continentally influenced air, which is also attributed to highly oxidised compounds from photochemical processes during transportation of these air masses (Dolgorouky et al., 2012). Similar reasons were reported by Lou et al. (2010) to account for missing OH reactivity measured in the highly populated Pearl River Delta.
Direct measurements of $\mathrm{OH}$ reactivity in rural areas generally tend to have larger missing $\mathrm{OH}$ reactivity. Using PTRMS and the CRM method in a boreal forest in Finland during August 2008, Sinha et al. (2010) reported missing OH reactivity of approximately $50 \%$. This site was revisited in 2010 , when missing $\mathrm{OH}$ reactivity of 58 to $89 \%$ was recorded (Nölscher et al., 2012a). Similar results in a mixed deciduous forest were obtained by Hansen et al. (2014), who reported missing $\mathrm{OH}$ reactivity of 46 to $65 \%$. Both studies concluded that unmeasured oxidation products were missing from the $\mathrm{OH}$ reactivity calculation. Undetected biogenic emissions and transport of reactive compounds are also cited as other reasons for missing $\mathrm{OH}$ reactivity. In contrast to those findings, Ren et al. (2006) found no significant missing $\mathrm{OH}$ reactivity on average during a summertime campaign in a deciduous forest in New York in 2002. They attributed this to differences in the composition of emitted biogenic VOCs (BVOCs). Rainforests are a large sink for $\mathrm{OH}$ as they emit a huge amount of VOCs. Measured $\mathrm{OH}$ reactivity in the rainforest of Borneo during April 2008 yielded a missing $\mathrm{OH}$ reactivity of $70 \%$ compared to calculated reactivity from measurements of single compounds (Edwards et al., 2013) and $\sim 53 \%$ compared to modelled reactivity (Whalley et al., 2011). Since isoprene makes up the biggest contribution to $\mathrm{OH}$ reactivity, the effect of oxidation products of isoprene was discussed (Edwards et al., 2013; Whalley et al., 2011).

While different possible explanations for missing $\mathrm{OH}$ reactivity have been given, the wide range in reported missing $\mathrm{OH}$ reactivity suggests that many reactants and processes remain unknown or cannot be measured at present. Measurements of total non-methane organic carbon in the western Los Angeles Basin (Chung et al., 2003) and results following the application of a double-column (orthogonal) GC for urban air measurements (Lewis et al., 2000) emphasise the large number of $\mathrm{OH}$ reactants that are not measured with standard field equipment.

Measurements of non methane hydrocarbons (NMHCs) used for calculation of $\mathrm{OH}$ reactivity are often performed with GC (Lou et al., 2010; Sadanaga et al., 2005; Shirley et al., 2006) and therefore the time resolution of the calculated $\mathrm{OH}$ reactivity is low due to long sampling and run times, e.g. canister samples once every hour (Kovacs et al., 2003; Sadanaga et al., 2005; Yoshino et al., 2006), when compared to measured total $\mathrm{OH}$ reactivity. However, the sampling time during one GC cycle is often shorter than the analysis time, and thus any high temporal variability in measured $\mathrm{OH}$ reactivity is not easily captured when it is derived from GC data (Nölscher et al., 2012a). When measured and calculated $\mathrm{OH}$ reactivity are compared, high-time-resolution data are often averaged over intervals that correspond to the GC cycle. The GC-FID systems for measurements of NMHCs used by Dolgorouky et al. (2012), for example, were sampling over $10 \mathrm{~min}$ and had an additional analysis run time of $20 \mathrm{~min}$, resulting in a time resolution of $30 \mathrm{~min}$. Their GC-MS for measurements of OVOCs used a sampling time of $30 \mathrm{~min}$, 
resulting in an overall time resolution of $90 \mathrm{~min}$, corresponding to the frequency they calculated $\mathrm{OH}$ reactivity.

This work addresses the question of how temporal VOC concentration variability is reflected with different sampling time resolutions. Furthermore, the effect of averaging VOC data on calculated $\mathrm{OH}$ reactivity is discussed alongside how this may affect the amount of "missing" $\mathrm{OH}$ reactivity.

Relatively high time-resolved VOC data collected by PTRToF-MS are used to calculate $\mathrm{OH}$ reactivity for selected compounds. Differing time resolutions are analysed to explore the effects. Data from an urban winter campaign are compared to measurements from a semi-rural summer campaign.

\section{Experimental section}

Two different sets of VOC mixing ratios measured with PTRToF-MS were used for analysis. One was collected during the ClearfLo (Clean Air for London, www.clearflo.ac.uk) (Bohnenstengel et al., 2015) winter campaign in 2012 at an urban background site in London, UK. The second was taken during the PARADE (PArticles and RAdicals: Diel observations of the impact of urban and biogenic Emissions, http://parade2011.mpich.de/) campaign in late summer 2011 at a semi-rural site located in the Taunus ridge, Germany.

\subsection{Field data}

\subsubsection{ClearfLo}

A PTR-ToF-MS (Series I; Kore Technology Ltd, UK) (see standard PTR-MS apparatus in Barber et al., 2012; Thalman et al., 2015) was deployed at Sion-Manning School $\left(51^{\circ} 31^{\prime} 15^{\prime \prime} \mathrm{N}, 0^{\circ} 12^{\prime} 51^{\prime \prime} \mathrm{W}\right)$ near the North Kensington urban background station in London during the intensive observation periods of the ClearfLo project in 2012. A general overview of the ClearfLo project and the measurement site is given in Bohnenstengel et al. (2015). For background measurements a hydrocarbon trap (activated carbon filter by Grace Alltech) was employed once during the time period investigated here. Its efficiency was in the range of 87-96\%. Calibration measurements were performed before (acetone) and after (toluene and xylene) the campaign in the laboratory. For the calibration of toluene and xylene a permeation tube was used, and calibration of acetone was done by dilution of a gas standard with zero air. The stability of the instrument during the campaign was monitored with a bromobenzene internal standard. Based on these measurements no correction needed to be applied. Of the two intensive observation periods (IOPs) (i.e. winter: 6 January to 11 February; summer: 21 July to 23 August) data from 1 to 7 February 2012 were selected for analysis in this study. During this period the measurement site was influenced by local sources, as well as by air masses from other parts of the UK and the continent (Bohnenstengel et al., 2015).
A dual-channel GC with flame ionisation detector (DCGC-FID; Hopkins et al., 2003) was deployed at the same site as the PTR-ToF-MS during the ClearfLo IOPs. A wide range of VOCs, including alkanes, alkenes, dienes, aromatic compounds and OVOCs, were measured (see Table 1). Stainless steel tubing heated to $80^{\circ} \mathrm{C}$ was used as a sampling line. This setup ensured the destruction of ozone present in the sample. The sampling time was $10 \mathrm{~min}$, while the analysis runtime was around $50 \mathrm{~min}$, resulting in approximately one measurement per hour.

\subsubsection{PARADE}

For comparison, data collected with a PTR-ToF-MS (Ionicon Analytik GmbH, Austria) (described in Jordan et al., 2009) during the PARADE field campaign were analysed. Measurements were taken between 15 August and 9 September 2011 at the Taunus observatory on the summit of Kleiner Feldberg $\left(50^{\circ} 13^{\prime} 25^{\prime \prime} \mathrm{N}, 8^{\circ} 26^{\prime} 56^{\prime \prime} \mathrm{E}\right)$ under various meteorological conditions. A detailed description of the measurement site and measurements performed during PARADE can be found in Crowley et al. (2010) and Bonn et al. (2014). The PTR-ToF-MS was operated continuously with minor interruptions. Background measurements were conducted regularly with zero air throughout the campaign and calibration measurements were performed with a multicomponent gas standard before and after the campaign in the laboratory. For this study, 2 weeks of data (21 to 27 August 2011 - Period 1; 1 to 6 September 2011 - Period 2) were selected, each with approximately the same amount of data points as the ClearfLo data set. Period 1 was mainly influenced by continental air masses and only towards the end by air that travelled over the UK and the English Channel (UK-marine). Period 2 was dominated by UK-marine air, but was also influenced by air masses that travelled over the Atlantic (see Phillips et al., 2012).

\subsubsection{Data}

While the ClearfLo data presented here were collected at an urban background site with mainly anthropogenic emissions, the PARADE campaign took place at a semi-rural site. Biogenic emissions were expected from the direct vicinity, but some anthropogenic influence was apparent from the proximity of the highly populated Rhein-Main area and Frankfurt.

Three mass channels were selected for the analysis corresponding to acetone/propanal, toluene and ethylbenzene/xylene. For brevity, the combined signal of acetone and propanal is referred to as acetone, and that of ethylbenzene and xylene is referred to as xylene. The compounds used for analysis represent different sources of VOCs. Toluene and xylene are counted along anthropogenic VOCs, monoterpenes are of biogenic origin, and the OVOCs (acetone and methanol) are emitted directly or produced by photochemi- 
Table 1. Mean mixing ratios and concentrations with standard deviation, rate coefficient and $\mathrm{OH}$ reactivity of the VOCs measured with DC-GC-FID during ClearfLo from 1 to 7 February 2012.

\begin{tabular}{|c|c|c|c|c|}
\hline Compound & VMR (ppbV) & $\begin{array}{c}\text { Concentration } \\
\left(\text { molecules } \mathrm{cm}^{-3}\right)\end{array}$ & $\begin{array}{c}k_{\mathrm{OH}} \\
\left(\mathrm{cm}^{3} \text { molecules }^{-1} \mathrm{~s}^{-1}\right)\end{array}$ & $\begin{array}{l}\text { OH reactivity } \\
\qquad\left(\mathrm{s}^{-1}\right)\end{array}$ \\
\hline \multicolumn{5}{|l|}{ Alkanes } \\
\hline Ethane $^{\mathrm{a}}$ & $12.91 \pm 10.89$ & $(3.14 \pm 2.65) \times 10^{11}$ & $2.40 \times 10^{-13}$ & 0.075 \\
\hline Propane $^{\mathrm{a}}$ & $4.59 \pm 3.35$ & $(1.12 \pm 0.81) \times 10^{11}$ & $1.10 \times 10^{-12}$ & 0.123 \\
\hline iso-Butane $\mathrm{e}^{\mathrm{b}}$ & $1.42 \pm 1.00$ & $(3.45 \pm 2.43) \times 10^{10}$ & $2.12 \times 10^{-12}$ & 0.073 \\
\hline$n$-Butane $\mathrm{e}^{\mathrm{b}}$ & $2.35 \pm 1.60$ & $(5.71 \pm 3.89) \times 10^{10}$ & $2.36 \times 10^{-12}$ & 0.135 \\
\hline Cyclopentane $\mathrm{b}^{\mathrm{b}}$ & $0.10 \pm 0.11$ & $(2.50 \pm 2.58) \times 10^{9}$ & $4.97 \times 10^{-12}$ & 0.012 \\
\hline iso-Pentane $\mathrm{e}^{\mathrm{b}}$ & $0.83 \pm 0.62$ & $(2.03 \pm 1.50) \times 10^{10}$ & $3.60 \times 10^{-12}$ & 0.073 \\
\hline$n$-Pentane $\mathrm{e}^{\mathrm{b}}$ & $0.42 \pm 0.26$ & $(1.02 \pm 0.64) \times 10^{10}$ & $3.80 \times 10^{-12}$ & 0.039 \\
\hline 2,3-Methylpentane $\mathrm{e}^{\mathrm{b} *}$ & $0.35 \pm 0.29$ & $(8.56 \pm 6.93) \times 10^{9}$ & $3.10 \times 10^{-11}$ & 0.265 \\
\hline$n$-Hexane $\mathrm{b}^{\mathrm{b}}$ & $0.13 \pm 0.09$ & $(3.16 \pm 2.29) \times 10^{9}$ & $5.20 \times 10^{-12}$ & 0.016 \\
\hline$n$-Heptane $\mathrm{b}^{\mathrm{b}}$ & $0.09 \pm 0.07$ & $(2.18 \pm 1.58) \times 10^{9}$ & $6.76 \times 10^{-12}$ & 0.015 \\
\hline $2,2,4-\mathrm{TMP}^{\mathrm{b}}$ & $0.04 \pm 0.02$ & $(9.88 \pm 5.22) \times 10^{8}$ & $3.34 \times 10^{-12}$ & 0.003 \\
\hline$n$-Octane $\mathrm{e}^{\mathrm{b}}$ & $0.03 \pm 0.02$ & $(6.75 \pm 3.75) \times 10^{8}$ & $8.11 \times 10^{-12}$ & 0.005 \\
\hline \multicolumn{5}{|l|}{ Alkenes } \\
\hline Ethene $^{\mathrm{a}}$ & $1.93 \pm 1.04$ & $(4.68 \pm 2.52) \times 10^{10}$ & $7.80 \times 10^{-12}$ & 0.365 \\
\hline Propene $^{a}$ & $0.43 \pm 0.30$ & $(1.05 \pm 0.73) \times 10^{10}$ & $2.90 \times 10^{-11}$ & 0.306 \\
\hline trans-2-Butene $^{\mathrm{b}}$ & $0.04 \pm 0.03$ & $(1.03 \pm 0.81) \times 10^{9}$ & $6.40 \times 10^{-11}$ & 0.066 \\
\hline 1 -Butene ${ }^{b}$ & $0.08 \pm 0.05$ & $(1.90 \pm 1.21) \times 10^{9}$ & $3.14 \times 10^{-11}$ & 0.060 \\
\hline iso-Butene ${ }^{\mathrm{a}}$ & $0.11 \pm 0.07$ & $(2.63 \pm 1.77) \times 10^{9}$ & $5.10 \times 10^{-11}$ & 0.134 \\
\hline cis-2-Butene $^{\mathrm{b}}$ & $0.03 \pm 0.02$ & $(6.92 \pm 5.72) \times 10^{8}$ & $5.64 \times 10^{-11}$ & 0.039 \\
\hline trans-2-Pentene $^{\mathrm{b}}$ & $0.04 \pm 0.03$ & $(9.13 \pm 7.37) \times 10^{8}$ & $6.70 \times 10^{-11}$ & 0.061 \\
\hline 1-Pentene ${ }^{b}$ & $0.03 \pm 0.02$ & $(7.32 \pm 5.27) \times 10^{8}$ & $3.14 \times 10^{-11}$ & 0.023 \\
\hline Acetylene $^{\mathrm{a}}$ & $1.43 \pm 0.74$ & $(3.47 \pm 1.81) \times 10^{10}$ & $7.50 \times 10^{-13}$ & 0.026 \\
\hline \multicolumn{5}{|l|}{ Dienes } \\
\hline Propadiene $\mathrm{b}^{\mathrm{b}}$ & $0.02 \pm 0.01$ & $(4.40 \pm 2.61) \times 10^{8}$ & $9.82 \times 10^{-12}$ & 0.004 \\
\hline 1,3-Butadiene ${ }^{\mathrm{b}}$ & $0.05 \pm 0.03$ & $(1.14 \pm 0.76) \times 10^{9}$ & $6.66 \times 10^{-11}$ & 0.076 \\
\hline Isoprene $^{\mathrm{a}}$ & $0.02 \pm 0.02$ & $(5.37 \pm 4.07) \times 10^{8}$ & $1.00 \times 10^{-10}$ & 0.054 \\
\hline \multicolumn{5}{|l|}{ Aromatic compounds } \\
\hline Benzene $^{a}$ & $0.41 \pm 0.17$ & $(9.88 \pm 4.06) \times 10^{9}$ & $1.20 \times 10^{-12}$ & 0.012 \\
\hline Toluene $^{\mathrm{a}}$ & $0.64 \pm 0.48$ & $(1.56 \pm 1.17) \times 10^{10}$ & $5.60 \times 10^{-12}$ & 0.087 \\
\hline Ethylbenzene $^{\mathrm{b}}$ & $0.14 \pm 0.11$ & $(3.48 \pm 2.57) \times 10^{9}$ & $7.00 \times 10^{-12}$ & 0.024 \\
\hline$m+p$-Xylene $\mathrm{b}^{\mathrm{b} *}$ & $0.18 \pm 0.14$ & $(4.28 \pm 3.52) \times 10^{9}$ & $1.87 \times 10^{-11}$ & 0.080 \\
\hline$o$-Xylene ${ }^{\mathrm{b}}$ & $0.17 \pm 0.12$ & $(4.02 \pm 2.82) \times 10^{9}$ & $1.36 \times 10^{-11}$ & 0.055 \\
\hline \multicolumn{5}{|l|}{ Oxygenated VOCs } \\
\hline Acetaldehyde $^{\mathrm{a}}$ & $2.37 \pm 1.38$ & $(5.77 \pm 3.35) \times 10^{10}$ & $1.50 \times 10^{-11}$ & 0.866 \\
\hline $\mathrm{MACR}^{\mathrm{b}}$ & $0.16 \pm 0.12$ & $(3.89 \pm 2.97) \times 10^{9}$ & $2.90 \times 10^{-11}$ & 0.113 \\
\hline Methanol $^{\mathrm{a}}$ & $1.44 \pm 0.81$ & $(3.50 \pm 1.96) \times 10^{10}$ & $9.00 \times 10^{-13}$ & 0.031 \\
\hline Acetone $^{\mathrm{a}}$ & $1.11 \pm 0.51$ & $(2.69 \pm 1.24) \times 10^{10}$ & $1.80 \times 10^{-13}$ & 0.005 \\
\hline $\mathrm{MVK}^{\mathrm{b}}$ & $0.28 \pm 0.15$ & $(6.72 \pm 3.61) \times 10^{9}$ & $2.00 \times 10^{-11}$ & 0.134 \\
\hline Ethanol $^{\mathrm{a}}$ & $5.48 \pm 3.81$ & $(1.33 \pm 0.93) \times 10^{11}$ & $3.20 \times 10^{-12}$ & 0.426 \\
\hline Propanol $^{\mathrm{a}}$ & $0.31 \pm 0.21$ & $(7.41 \pm 5.15) \times 10^{9}$ & $5.80 \times 10^{-12}$ & 0.043 \\
\hline Butanol $^{\mathrm{a}}$ & $0.59 \pm 0.33$ & $(1.45 \pm 0.80) \times 10^{10}$ & $8.50 \times 10^{-12}$ & 0.123 \\
\hline
\end{tabular}

a IUPAC preferred value; ${ }^{\text {b }}$ Atkinson and Arey (2003); * average of both. 

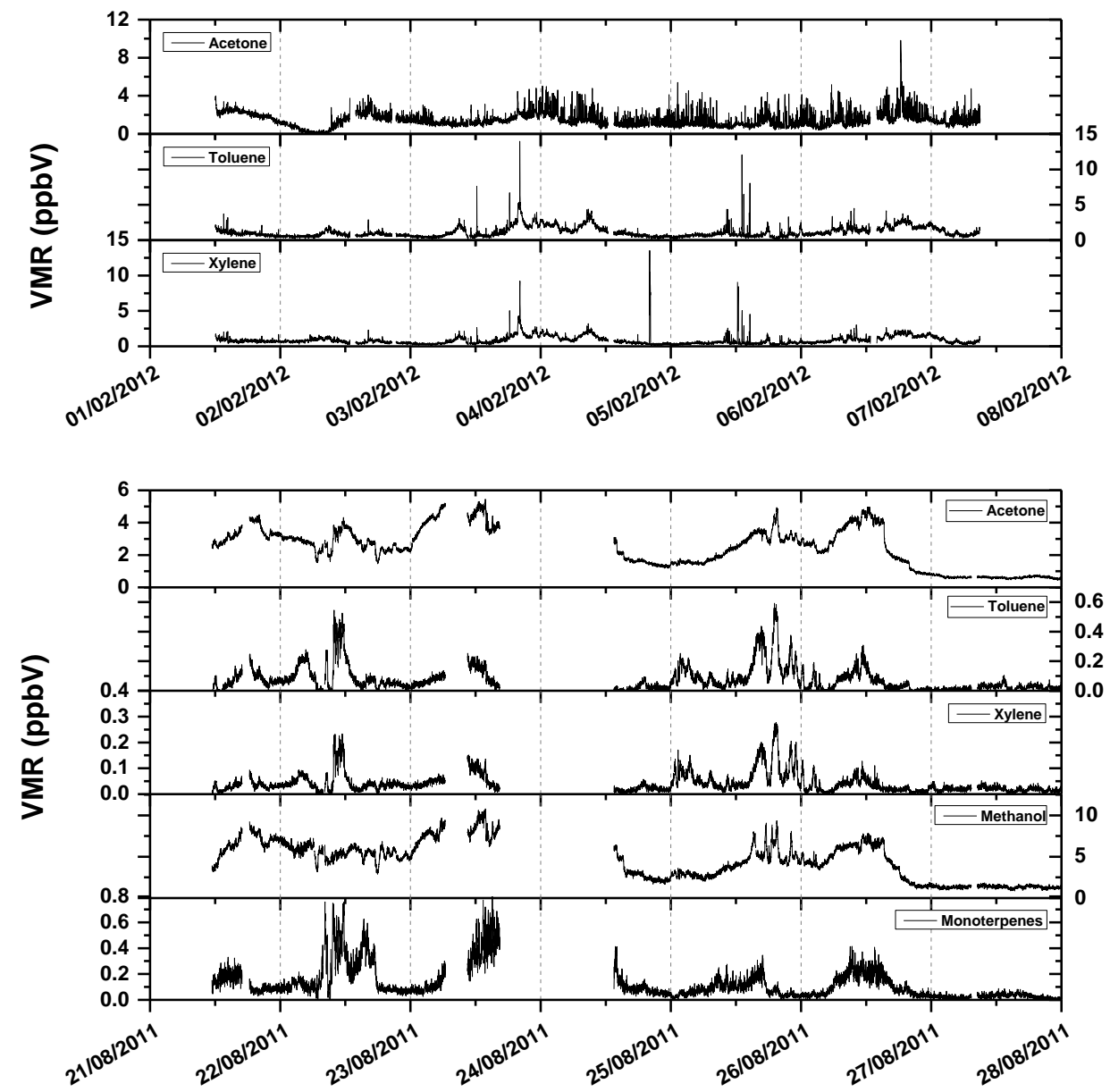

Figure 1. Time series of VOCs during ClearfLo (top) and PARADE Period 1 (bottom). The time resolution is $1 \mathrm{~min}$.

cal oxidation in the atmosphere (Monks et al., 2009, and references therein). They were selected because their volume mixing ratios could be determined with low uncertainty for both instruments. Aromatic compounds such as toluene and xylene are well suited for this investigation because they often show short-term high variability. The analysis of the PARADE data also includes methanol and the sum of monoterpenes. The characteristic parameters of the measurements during ClearfLo and PARADE are given in Table 2.

Figure 1 shows the time series of the VOCs for ClearfLo (top) and PARADE Period 1 (bottom). The range of mixing ratios for ClearfLo is much wider and higher mixing ratios are reached. Acetone shows values up to a factor of 1.8 higher in ClearfLo compared to PARADE, while the aromatic compounds are 2 orders of magnitude higher. This emphasises the diversity of the two field sites. In the box plots, presented in Fig. 2, some interesting patterns are apparent. For ClearfLo all three compounds exhibit a similar interquartile range ( 0.60 to $0.86 \mathrm{ppbV})$ but also very high maximum values. For PARADE a different distribution is depicted. Acetone has a wider interquartile range of $1.83 \mathrm{ppbV}$ and has a higher mean value than toluene and xylene. The aromatic compounds have a much smaller range compared to ClearfLo (0.03 to $0.08 \mathrm{ppbV}$ ). Methanol has a wider range than acetone and the monoterpenes look similar to the aromatic compounds. Both periods of PARADE show the same pattern. The ranges of the mixing ratios during the campaigns are summarised in Table 3. Values below the limit of detection (LOD) as well as negative values are not disregarded in this analysis to preserve the full range of the data in order that they can be compared to a randomly generated data set.

$\mathrm{OH}$ reactivity relating to the VOCs under study is calculated from the first term of Eq. (1). Reaction rates for acetone $\left(1.8 \times 10^{-13} \mathrm{~cm}^{3}\right.$ molecule $\left.\mathrm{e}^{-1} \mathrm{~s}^{-1}\right)$, toluene $\left(5.6 \times 10^{-12} \mathrm{~cm}^{3}\right.$ molecule $\left.{ }^{-1} \mathrm{~s}^{-1}\right)$, methanol $\left(9.0 \times 10^{-13} \mathrm{~cm}^{3}\right.$ molecule $\left.{ }^{-1} \mathrm{~s}^{-1}\right) \quad$ and $\alpha$-pinene $\left(5.3 \times 10^{-11} \mathrm{~cm}^{3}\right.$ molecule $\left.{ }^{-1} \mathrm{~s}^{-1}\right)$ are taken from http://iupac.pole-ether.fr/index.html. The exact composition of the monoterpene signal is not known; thus, only the reaction rate of $\alpha$-pinene is used. For xylene the average of the reaction rates of ethylbenzene and $o-, m$ - and $p$-xylene $\left(14.5 \times 10^{-12} \mathrm{~cm}^{3}\right.$ molecule $\left.{ }^{-1} \mathrm{~s}^{-1}\right)$ (Atkinson and Arey, 
Table 2. Characteristics of the two different PTR-ToF-MS deployed during ClearfLo and PARADE. Given are the sensitivities based on normalised counts per second (ncps), accuracy as error for the measurements, and the limit of detection (LOD), which was calculated as $1 \sigma$ for ClearfLo and $2.6 \sigma$ for PARADE based on 1 min data.

\begin{tabular}{|c|c|c|c|c|}
\hline & Compound & $\begin{array}{r}\text { Sensitivity } \\
\left(\text { ncps } \mathrm{ppbV}^{-1}\right)\end{array}$ & $\begin{array}{r}\text { Accuracy } \\
(\%)\end{array}$ & $\begin{array}{r}\mathrm{LOD}(1 \sigma) \\
(\mathrm{ppbV})\end{array}$ \\
\hline \multirow{4}{*}{ ClearfLo } & Acetone & 9.89 & $18^{*}$ & 0.56 \\
\hline & Toluene & 6.36 & $18 *(22)$ & 0.38 \\
\hline & Xylene & 9.00 & $18^{*}(20)$ & 0.41 \\
\hline & Compound & $\begin{array}{r}\text { Sensitivity } \\
\left(\text { ncps ppbV }{ }^{-1}\right)\end{array}$ & $\begin{array}{r}\text { Accuracy } \\
(\%)\end{array}$ & $\begin{array}{r}\text { LOD }(2.6 \sigma) \\
(\mathrm{ppbV}) \\
\end{array}$ \\
\hline \multirow{5}{*}{ PARADE } & Acetone & 37.0 & 16 & 0.08 \\
\hline & Toluene & 26.9 & 8 & 0.04 \\
\hline & Xylene & 33.4 & 13 & 0.01 \\
\hline & Methanol & 12.7 & 17 & 0.24 \\
\hline & Monoterpenes & 14.1 & 10 & 0.02 \\
\hline
\end{tabular}

Effects of isobaric overlap from fragmentation taken into account. *First column does not include effect of isobaric overlap from aromatic fragmentation; second column includes estimation of isobaric overlap.

Table 3. Overview of the range of VOC mixing ratios in ppbV during ClearfLo and PARADE (PAR).

\begin{tabular}{llrrrrr}
\hline & & Minimum & Maximum & Mean & Interquart. range & Max-Min \\
\hline \multirow{2}{*}{ ClearfLo } & Acetone & -0.294 & 9.816 & 1.459 & 0.864 & 10.110 \\
& Toluene & 0.058 & 13.982 & 1.162 & 0.862 & 13.924 \\
& Xylene & 0.038 & 13.519 & 0.861 & 0.601 & 13.482 \\
\hline \multirow{2}{*}{ PAR 1 } & Acetone & 0.426 & 5.447 & 2.400 & 1.833 & 5.021 \\
& Toluene & -0.030 & 0.592 & 0.076 & 0.078 & 0.622 \\
& Xylene & -0.008 & 0.277 & 0.041 & 0.030 & 0.285 \\
& Methanol & 0.851 & 10.775 & 4.438 & 3.858 & 9.923 \\
& Monoterp. & -0.008 & 0.801 & 0.124 & 0.116 & 0.809 \\
\hline \multirow{2}{*}{ PAR 2 } & Acetone & 0.544 & 4.873 & 1.987 & 1.797 & 4.329 \\
& Toluene & -0.017 & 0.646 & 0.078 & 0.073 & 0.663 \\
& Xylene & -0.004 & 0.358 & 0.046 & 0.039 & 0.362 \\
& Methanol & 0.781 & 10.649 & 3.776 & 2.739 & 9.869 \\
& Monoterp. & -0.009 & 0.692 & 0.075 & 0.086 & 0.701 \\
\hline
\end{tabular}

2003) was applied. Table 4 summarises the minimum, maximum and mean reactivity calculated from these VOCs as described.

The time resolution of PTR-ToF-MS is only limited by the signal-to-noise ratio and resulting detection limit. Both instruments were operated with a 1 min time resolution. Volume mixing ratios of VOCs were averaged over different intervals and standard deviations were derived. An average was only included for analysis if its data recovery was at least $50 \%$. The $\mathrm{OH}$ reactivity for each VOC was calculated and summed as required. Only the standard deviations were propagated as errors of reactivity, as the focus of this work is on investigating VOC variability.

For clarity throughout this paper the notation $R=R_{\mathrm{OH}}$ for reactivity regarding the $\mathrm{OH}$ radical replaces $k_{\mathrm{OH}}$ (see Eq. 1; see also Nölscher et al., 2012a). Indices denote the origin of the data (PTR (PTR-ToF-MS) or GC (DC-GC-FID) and CL (ClearfLo) or PAR (PARADE)). Numbers indicate the averaging time in minutes. If only some VOCs are taken into account for calculating the reactivity, this will be indicated, e.g. $R_{\mathrm{PTR}, \mathrm{CL}}^{\mathrm{OVO}, 5}$ is the $\mathrm{OH}$ reactivity calculated from the $5 \mathrm{~min}$ mean concentration of acetone, measured with the PTR-ToFMS during ClearfLo.

\subsection{Distribution of $\mathrm{OH}$ reactivity of measured VOCs}

For a more general view of the factors that drive variation in $\mathrm{OH}$ reactivity of VOCs, its frequency distribution was investigated. GC data from the winter (9 January-9 February 2012) and summer IOP (18 July-19 August 2012) during ClearfLo were applied. The $\mathrm{OH}$ reactivity, $R_{\mathrm{GC}, \mathrm{CL}}^{\mathrm{VOC}_{i}}$, was calculated for each measured $\mathrm{VOC}_{i}$ and ranged from 0.003 

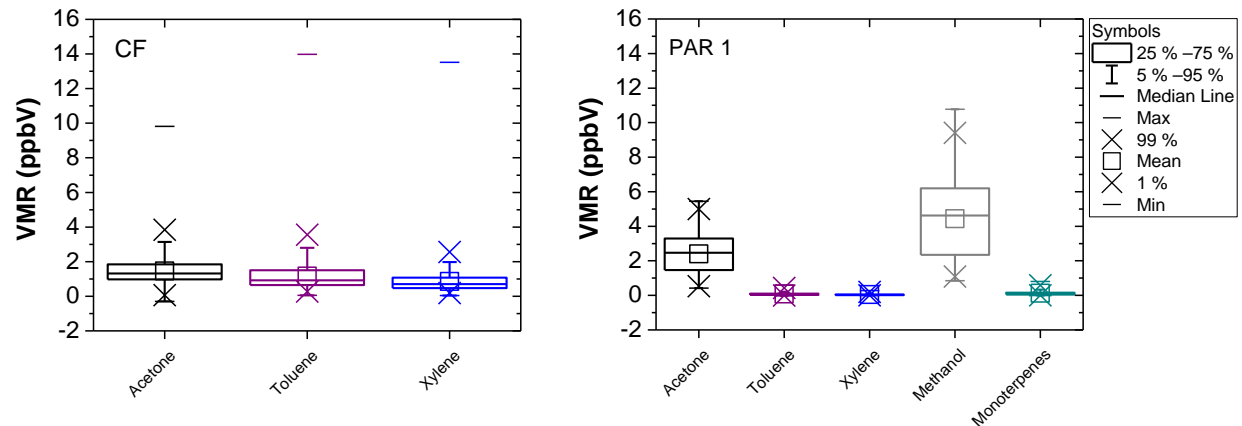

Figure 2. Box plots for ClearfLo (left) and PARADE Period 1 (right) showing the minimum, maximum, mean (), median, interquartile range (box) and percentiles at 1 and $99 \%(x)$.

Table 4. Minimum, maximum and mean $\mathrm{OH}$ reactivity and standard deviation calculated from the VOCs under study for ClearfLo and PARADE.

\begin{tabular}{llrrrr}
\hline \multicolumn{2}{c}{ OH reactivity $\left(\mathrm{s}^{-1}\right)$} & Minimum & Maximum & Mean & SD \\
\hline CF & ATX & 0.036 & 4.864 & 0.463 & 0.289 \\
\hline PAR1 & ATX & 0.000 & 0.191 & 0.035 & 0.028 \\
& ATX+M+MT & 0.026 & 1.296 & 0.292 & 0.205 \\
\hline \multirow{2}{*}{ PAR2 } & ATX & 0.001 & 0.222 & 0.036 & 0.024 \\
& ATX+M+MT & 0.044 & 0.987 & 0.215 & 0.119
\end{tabular}

ATX: acetone, toluene and xylene. ATX+M+MT: acetone, toluene, xylene, methanol and monoterpenes

to $0.822 \mathrm{~s}^{-1}$ in winter and from 0.001 to $1.568 \mathrm{~s}^{-1}$ in summer with a total $\mathrm{OH}$ reactivity $R_{\mathrm{GC}, \mathrm{TL}}^{\mathrm{TVOC}} 4.010 \mathrm{~s}^{-1}$ and $3.862 \mathrm{~s}^{-1}$, respectively. The majority of $R_{\mathrm{GC}, \mathrm{CL}}^{\mathrm{VOC}_{i}}$ values lies below $0.1 \mathrm{~s}^{-1}$, as can be seen from the frequency distribution plotted in Fig. 3, where more than $70 \%$ of the winter and $80 \%$ of the summer data are in the first interval from 0 to $0.1 \mathrm{~s}^{-1}$. Seasonal differences in $\mathrm{OH}$ reactivity emission rates have previously been described by Nölscher et al. (2013) for measurements at a Norway spruce between spring and early autumn. Although the composition of VOCs during ClearfLo changed from winter to summer, no seasonal dependency could be found in the shape of the frequency distribution of $R_{\mathrm{GC}, \mathrm{CL}}^{\mathrm{VOC}}$. In both cases $R_{\mathrm{GC}, \mathrm{CL}}^{\mathrm{TVOC}}$ is dominated by the sum of low-reactivity contributions and less by single compounds with high reactivity.

\subsection{Generation of a randomised data set}

To differentiate between pure statistical effects and measurement related characteristics, a randomised data set was produced and analysed in the same way as the PTR-ToF-MS data. The distribution of $\mathrm{OH}$ reactivity is skewed towards smaller values and only positive values of $\mathrm{OH}$ reactivity are expected; hence, it is better described by a log-normal distribution compared to a normal distribution (Limpert et al., 2001). The data set of random numbers was generated by
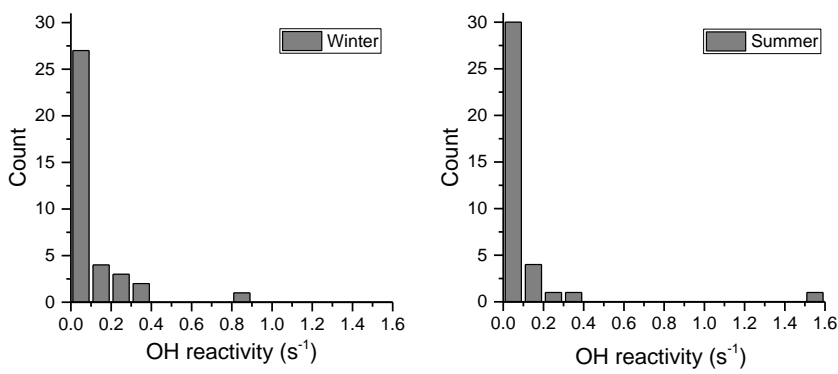

Figure 3. $\mathrm{OH}$ reactivity, $R_{\mathrm{GC}, \mathrm{CL}}^{\mathrm{VOC}_{i}}$, frequency distribution for the ClearfLo campaign in winter (left) and summer (right). Bin size is $0.1 \mathrm{~s}^{-1}$ for both plots.

simulating an $\mathrm{OH}$ reactivity distribution comparable to the ClearfLo data set. The sample mean $m=0.463 \mathrm{~s}^{-1}$ and standard deviation $\mathrm{SD}=0.289 \mathrm{~s}^{-1}$ from the ClearfLo 1 min data set were used to define the parameters $\mu$ (Eq. 2) and $\sigma$ (Eq. 3) for the log-normal distribution of random numbers.

$\mu=\log \left(\frac{m}{\sqrt{1+\frac{\mathrm{SD}^{2}}{m^{2}}}}\right)$
$\sigma=\sqrt{\log \left(1+\frac{\mathrm{SD}^{2}}{m^{2}}\right)}$

A log-normal distribution of a total of 8040 random numbers was generated using the dlnorm $(\#, \mu, \sigma)$ function in $R$. This provides a set of data comparable to $134 \mathrm{~h}$ of $\mathrm{OH}$ reactivity measurements with a time resolution of $1 \mathrm{~min}$. Figure 4 shows the random data set as a time series together with the hourly mean containing 60 data points. On inspection of Fig. 4, it becomes obvious that the range of the hourly average is very small, with a standard deviation of $0.034 \mathrm{~s}^{-1}$. 


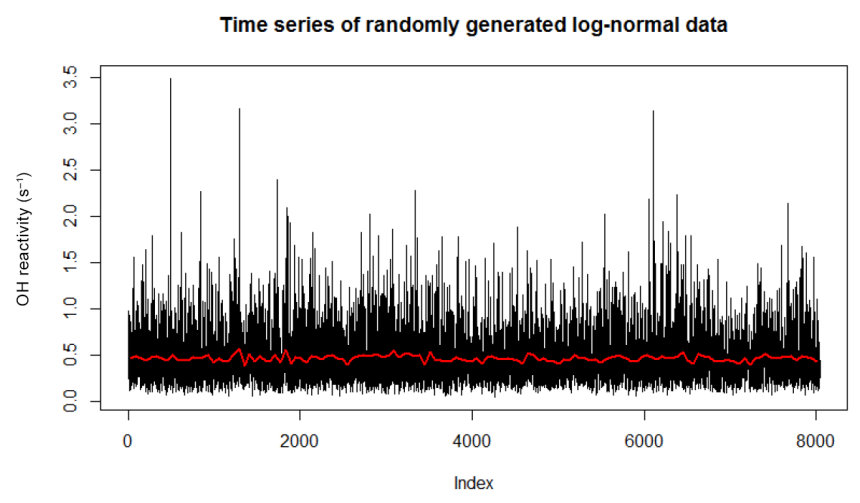

Figure 4. Time series of randomly generated log-normal data set containing 8040 numbers. The " 1 min" data are shown in black. The average over 60 data points is plotted in red.

\section{Results and discussion}

Initially the $\mathrm{OH}$ reactivity $R_{\mathrm{PTR}}^{\mathrm{VOC}}$ was calculated from the PTR data for ClearfLo and PARADE. For both campaigns the signals of acetone, toluene and xylene (referred to generally as VOCs) were used. The effects of differing sampling intervals on the derived reactivity were explored. For each campaign and VOC data set a correlation of the average values of $R_{\mathrm{PTR}}^{\mathrm{VOC}, t}$ for different intervals $(t=5,10,20$ and $30 \mathrm{~min}$ ) against the $60 \mathrm{~min}$ average $R_{\mathrm{PTR}}^{\mathrm{VOC}, 60}$ was calculated. The intervals are chosen to be the first $t$ minutes of each hour to simulate the initiation of a GC sequence; thus, the $10 \mathrm{~min}$ average also covers the $5 \mathrm{~min}$ averaging period and so on.

Figure 5 shows the linear correlation of the 5 min average $R_{\mathrm{PTR}, \mathrm{CL}}^{\mathrm{VOC}, 5}$ versus the $60 \mathrm{~min}$ value $R_{\mathrm{PTR}, \mathrm{CL}}^{\mathrm{VOC}, 60}$ for the ClearfLo winter campaign. Data were fitted with a bivariate regression line with an intercept (bvf) and forced through the origin (bvfo). The deviation from the slope of the linear regression to a unity gradient $m_{\text {res }}=\left(m_{R^{<60} / R^{60}}-1\right)$ is taken as a measure of how well the value of hourly $\mathrm{OH}$ reactivity is represented by the shorter interval average and is further referred to as the residual slope.

\subsection{Effects of different sampling intervals}

The slopes of both fits in Fig. 5 are below 1.0, indicating an under-prediction of the reactivity during ClearfLo by the value calculated from the first $5 \mathrm{~min}$ of each hour. In this case there is only a small deviation (1.3\%) from a unity gradient (see Fig. 6). For all averaging intervals the slope is equal to 1 in the range of the uncertainties of the fit.

For the different averaging intervals the difference to the hourly average $\left(\Delta R=R_{\mathrm{PTR}, \mathrm{VL}}^{\mathrm{VOC}}-R_{\mathrm{PTR}, \mathrm{CL}}^{\mathrm{VOC}, 60}\right)$ was calculated, and their standard deviations are given in Table 5 as a measure of variance. $\Delta R$ generally decreases with increasing averaging time. Also presented in Table 5 are the results from fitted Gaussian functions to the frequency distribution of the
Table 5. Standard deviation of $\Delta R$ and results from Gaussian fits of the ratio of $\mathrm{OH}$ reactivity $R_{\mathrm{PTR}, \mathrm{CL}}^{\mathrm{VOC}, t<60} / R_{\mathrm{PTR}, \mathrm{CL}}^{\mathrm{VOC},=60}$ calculated from shorter interval averages to $60 \mathrm{~min}$ average for ClearfLo.

\begin{tabular}{lrrrr}
\hline & & $\Delta R$ & Gaussian fit & \\
\hline Notation & $\begin{array}{r}\text { Time interval } \\
(\mathrm{min})\end{array}$ & $\begin{array}{r}\text { SD } \\
\left(\mathrm{s}^{-1}\right)\end{array}$ & Centre & FWHM \\
\hline$R_{\text {PTR,CL }}^{\text {VOC,5 }}$ & 5 & 0.12 & $0.998 \pm 0.011$ & $0.337 \pm 0.025$ \\
$R_{\text {PTR,CL }}^{\text {VOC,10 }}$ & 10 & 0.12 & $0.997 \pm 0.008$ & $0.244 \pm 0.020$ \\
$R_{\text {PTR,CL }}^{\text {VOC,20 }}$ & 20 & 0.10 & $0.988 \pm 0.006$ & $0.246 \pm 0.013$ \\
$R_{\text {PTR,CL }}^{\text {VOC,30 }}$ & 30 & 0.06 & $0.992 \pm 0.004$ & $0.198 \pm 0.009$ \\
\hline
\end{tabular}

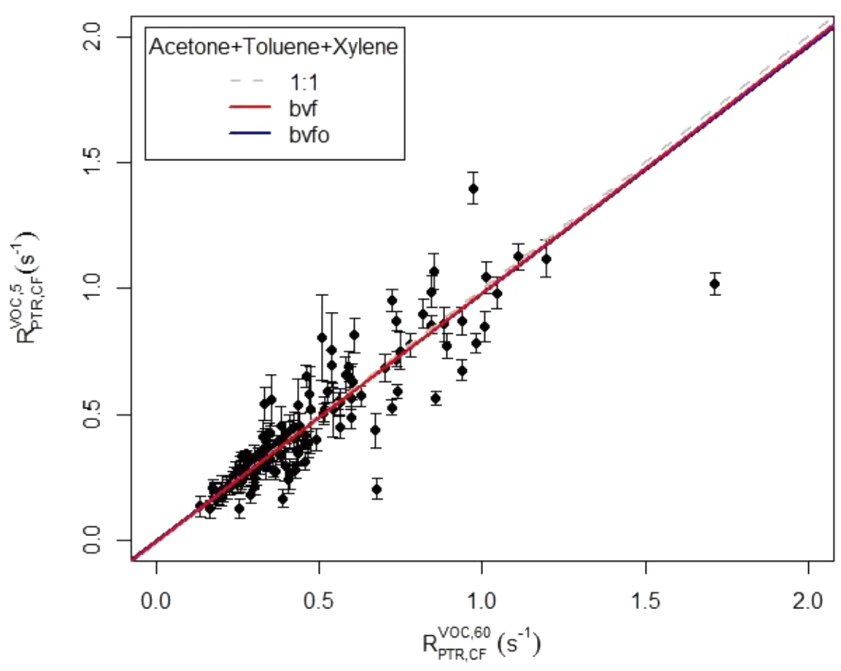

Figure 5. Linear correlation with bivariate fit (bvf: fit with intercept; bvfo: fit forced through the origin) of the $\mathrm{OH}$ reactivity calculated from the signals of acetone, toluene and xylene for average intervals of $5 \mathrm{~min}$ and $60 \mathrm{~min}$ for ClearfLo. The standard deviations of the 5 min means are plotted as error bars.

ratio of the shorter interval averages to the $60 \mathrm{~min}$ average. Bins of 0.1 were chosen for the frequency distributions. Ideally, the centre of the Gaussian fit is 1, while the full width at half maximum (FWHM) describes the spread of the distribution around its centre. Both the standard deviation of $\Delta R$ and the FWHM decrease when averages are calculated for longer intervals. The centres of all Gaussian fits achieve 0.99.

For Period 1 of the PARADE data (PAR1) the results show a slope greater than 1 (Fig. 7). The high variability in the data is reflected by a higher divergence of the slopes of 1.13 for bvf fit and 1.05 for the bvfo fit based on $5 \mathrm{~min}$ averaged data. The small standard deviations of $\Delta R$ given in Table 6 highlight the narrow range of calculated OH reactivity $R_{\mathrm{PTR}, \mathrm{VAR} 1}^{\mathrm{VOC}}$ However, the high variability in the data is reflected by the FWHM of the frequency distributions of the ratios, which is higher for each interval when compared to ClearfLo. 


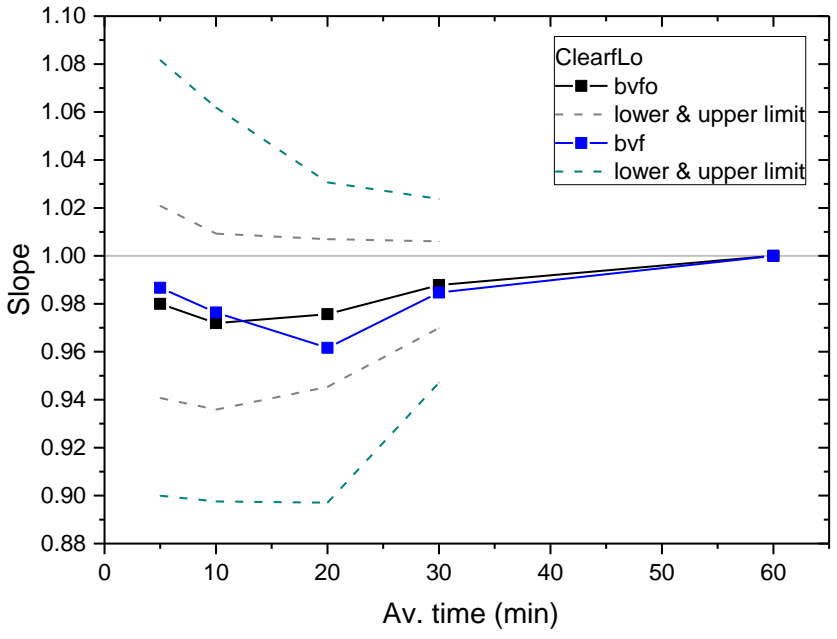

Figure 6. Development of the slope of the correlation of $\mathrm{OH}$ reactivity $R_{\mathrm{PTR}, \mathrm{CL}}^{\mathrm{VOC} t}$ depending on the sampling interval for ClearfLo. Slopes for bvfo (black) and bvf (blue) with their lower and upper limits are shown.

Table 6. Standard deviation of $\Delta R$ and results from Gaussian fits of the ratio of $\mathrm{OH}$ reactivity $R_{\mathrm{PTR}, \mathrm{PAR} 1}^{\mathrm{VOC},<6} R_{\mathrm{PTR}, \mathrm{PAR} 1}^{\mathrm{VOC}, t=60}$ calculated from shorter interval averages to $60 \mathrm{~min}$ average for PARADE - Period 1.

\begin{tabular}{lrrrr}
\hline & & $\Delta R$ & Gaussian fit & \\
\hline Notation & $\begin{array}{r}\text { Time interval } \\
(\mathrm{min})\end{array}$ & $\begin{array}{r}\text { SD } \\
\left(\mathrm{s}^{-1}\right)\end{array}$ & Centre & FWHM \\
\hline$R_{\text {PTR,PAR1 }}^{\text {VOC,5 }}$ & 5 & 0.016 & $0.980 \pm 0.011$ & $0.379 \pm 0.027$ \\
$R_{\text {PTR,PAR1 }}^{\text {VOC,10 }}$ & 10 & 0.015 & $0.976 \pm 0.012$ & $0.353 \pm 0.026$ \\
$R_{\text {PTR,PAR1 }}^{\text {VOC,20 }}$ & 20 & 0.012 & $0.997 \pm 0.013$ & $0.310 \pm 0.030$ \\
$R_{\text {PTR,PAR1 }}^{\text {VOC,30 }}$ & 30 & 0.008 & $0.995 \pm 0.009$ & $0.273 \pm 0.020$ \\
\hline
\end{tabular}

For Period 2 (PAR2), an over-prediction of the $\mathrm{OH}$ reactivity $R_{\mathrm{PTR}, \mathrm{PAR} 2}^{\mathrm{VOC}}$ can be observed again (Fig. 8), but with an even greater slope of 1.26. In both periods of PARADE the slope approaches a value of 1 as increasing averaging time takes more of the variability within $1 \mathrm{~h}$ into account. Standard deviations of $\Delta R$ and FWHM values are similar to Period 1 of the PARADE data, while the centres of the Gaussians are closer to 1 (Table 7).

When $\mathrm{OH}$ reactivity is calculated from GC measurements of VOCs, some of the variability in the data is not captured, because air sampling alternates with the GC run itself (Hopkins et al., 2003). In this manner, the analytes are collected for a short duration which is then used to represent the whole measurement cycle. This work suggests that a discrepancy between 60 min averages and shorter intervals can be caused owing to the variable nature of atmospheric VOCs. A sampling time of only 5 min can cause a deviation of more than $25 \%$. Accordingly, this would then artificially contribute to a deviation in $\mathrm{OH}$ reactivity, causing a positive or negative

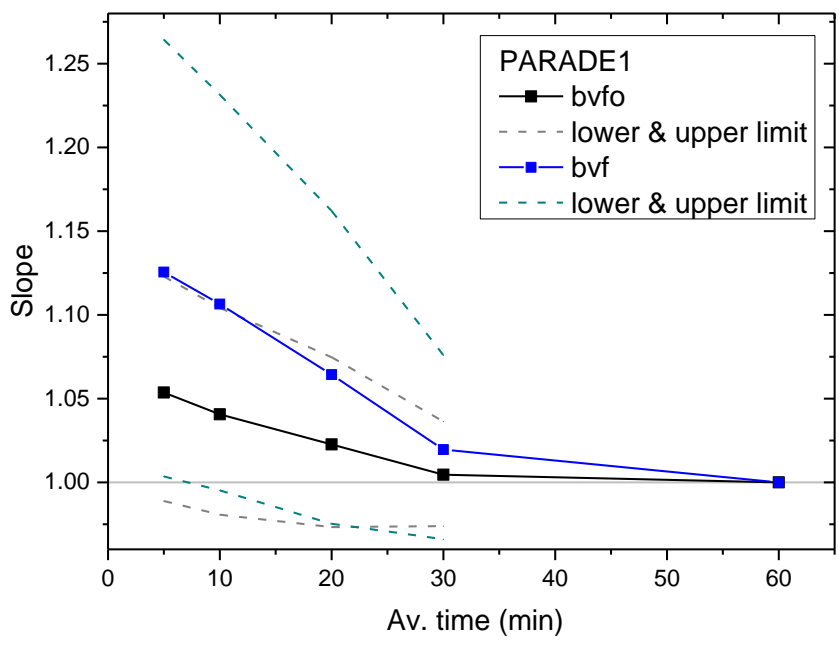

Figure 7. Development of the slope of the correlation of $\mathrm{OH}$ reactivity $R_{\mathrm{PTR}, \mathrm{PAR} 1}^{\mathrm{VOC}, t}$ depending on the averaging time for PARADE Period 1 .

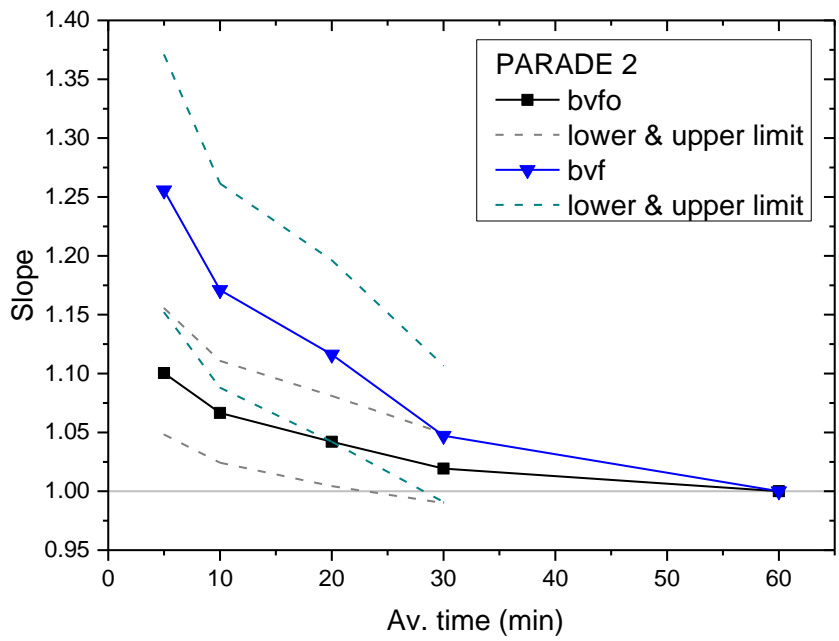

Figure 8. Development of the slope of the correlation of $\mathrm{OH}$ reactivity $R_{\mathrm{PTR}, \mathrm{PAR} 2}^{\mathrm{VOC}, t}$ depending on the averaging time for PARADE Period 2.

bias. Thereby, it is an additional error source when comparing measured total $\mathrm{OH}$ reactivity to $\mathrm{OH}$ reactivity calculated from GC data.

The deviation is greater for the semi-rural measurements in the Taunus during PARADE compared to the urban measurements in London. Although the range of the analysed $\mathrm{OH}$ reactivity of VOCs is smaller during PARADE, the highly frequent fluctuations cause a greater variability in $\mathrm{OH}$ reactivity for the investigated intervals. 
Table 7. Standard deviation of $\Delta R$ and results from Gaussian fits of the ratio of $\mathrm{OH}$ reactivity $R_{\mathrm{PTR}, \mathrm{PAR} 2}^{\mathrm{VOC},<6} / R_{\mathrm{PTR}, \mathrm{PAR} 2}^{\mathrm{VOC}, t=60}$ calculated from shorter interval averages to $60 \mathrm{~min}$ average for PARADE - Period 2.

\begin{tabular}{lrrrr}
\hline & & $\Delta R$ & Gaussian fit & \\
\hline Notation & $\begin{array}{r}\text { Time interval } \\
(\mathrm{min})\end{array}$ & $\begin{array}{r}\mathrm{SD} \\
\left(\mathrm{s}^{-1}\right)\end{array}$ & Centre & FWHM \\
\hline$R_{\mathrm{PTR}, \text { PAR2 }}^{\text {VOC,5 }}$ & 5 & 0.013 & $0.996 \pm 0.014$ & $0.352 \pm 0.034$ \\
$R_{\mathrm{PTR}, \text { PAR2 }}^{\text {VOC,0 }}$ & 10 & 0.009 & $0.994 \pm 0.013$ & $0.296 \pm 0.031$ \\
$R_{\mathrm{PTR}, \text { PAR2 }}^{\text {VOC }}$ & 20 & 0.008 & $0.992 \pm 0.008$ & $0.238 \pm 0.019$ \\
$R_{\text {PTR,PAR2 }}^{\text {VOC,30 }}$ & 30 & 0.006 & $1.010 \pm 0.004$ & $0.238 \pm 0.010$ \\
\hline
\end{tabular}

\subsection{The distribution of residual slopes across consecutive 5 min intervals}

In the previous section, only reactivity calculated from the average of the first $5,10,20$ and 30 min was compared to the hourly mean. Naturally, these averages have different values, depending on the point at which they are selected from the hour under study. They may over- or under-predict the hourly mean as can be seen from Fig. 9, where residual bvf slopes between $R_{\mathrm{PTR}}^{\mathrm{VOC}, 5}$ and $R_{\mathrm{PTR}}^{\mathrm{VOC}, 60}$ (see Fig. 5) are plotted for consecutive $5 \mathrm{~min}$ averaging periods within the hour. Depending on the selected $5 \mathrm{~min}$ interval the bvf resulted in a divergence of -0.1 to $44 \%$ for ClearfLo, 1 to $13 \%$ for PAR $1,-3$ to $26 \%$ for PAR 2 and -2 to $10 \%$ for the randomised data. A tendency towards an over-prediction of $\mathrm{OH}$ reactivity was observed for both campaigns (ClearfLo - top left; PARADE - bottom) and also for the randomised data set (top right). For the randomised data set bvfo was used - a bvf has a much higher slope as the data are clustered together within a small range. On average the residuals are nearly $10 \%$ with a standard deviation of $0.1 \%$ or less $(8.6 \% \pm 0.1 \%$ for ClearfLo; $8.85 \% \pm 0.03 \%$ for PARADE $1 ; 9.5 \% \pm 0.1 \%$ for PARADE $2 ; 4 \% \pm 4 \%$ for the randomised data).

For linear regression the standard least-squares fit is widely used. This method is less adequate when errors in both $y$ and $x$ are assumed or when the assignment of the independent variable is not clear (Isobe et al., 1990). Other methods for bivariate fitting in natural sciences have been discussed in the literature (Cantrell, 2008; Isobe et al., 1990; Warton et al., 2006). Cantrell (2008) found that a bivariate fit is less sensitive to outliers compared to an ordinary least-squares (ols) fit. Warton et al. (2006) described the major axis (ma) and standard or reduced major axis regression (sma/rma). These methods are preferred when the agreement between two measurement techniques is investigated. For equally important deviations from the regression line in the $x$ and $y$ directions ma is used, while sma can be used when the scales in $x$ and $y$ are not comparable. These two functions are implemented in the smatr package in R. The
Table 8. Summary of the statistics of the residual slopes and ratios from the comparisons of the $5 \mathrm{~min}$ means to their $60 \mathrm{~min}$ means for the ClearfLo data.

\begin{tabular}{lrrrrr}
\hline Method & Min & Max & Range & Mean & SD \\
\hline ols & -0.129 & 0.250 & 0.379 & -0.008 & 0.112 \\
ols-bis & -0.119 & -0.024 & 0.094 & -0.080 & 0.036 \\
bvfo & -0.033 & 0.116 & 0.149 & 0.014 & 0.043 \\
bvf & -0.019 & 0.443 & 0.462 & 0.861 & 0.130 \\
Ratio & -0.030 & 0.031 & 0.061 & -0.006 & 0.017 \\
\hline
\end{tabular}

ma function is used to produce the bivariate regression line (bvf) and the bivariate regression forced through the origin (bvfo) in this work. In the work of Isobe et al. (1990) the ordinary least-squares regression, major axis and reduced major axis regression, and additionally ols bisector (ols-bis) regression, are compared. They point out that different slopes are to be expected for all the bivariate fits (ma, sma, ols-bis). For ma they find large uncertainties for the slope. To carry out a symmetrical analysis they recommend using the ols-bis regression.

Figure 10 shows the residual slopes between $R_{\mathrm{PTR}, \mathrm{CL}}^{\mathrm{VOC}, 5}$ and $R_{\mathrm{PTR}, \mathrm{VL}}^{\mathrm{VOC}, 00}$ for consecutive $5 \mathrm{~min}$ intervals of the ClearfLo data using the different regression methods (ols, ols-bis, bvfo, bvf). The mean of the residual ratios (i.e. the average ratio minus 1) of $R_{\mathrm{PTR}, \mathrm{VL}}^{\mathrm{VOC}}$ to $R_{\mathrm{PTR}, \mathrm{CL}}^{\mathrm{VOC}, 60}$ is also shown in Fig. 10 . The bvfo puts more weight onto low $\mathrm{OH}$ reactivity values compared to bvf and produces a line that much better matches the majority of the data. Therefore smaller residuals are observed compared to the bvf. The very small residual of the average ratio also emphasise that deviation from the ideal slope of 1 is mainly driven by outliers. The ols-bis regression shows a negative residual for all $5 \mathrm{~min}$ intervals. Mean deviations and ranges for all regression methods based on consecutive 5 min averaging periods are summarised in Table 8 , where it can clearly be seen that ols and the ratio have a negligible deviation once averaged across 12 intervals. On average the ols shows the smallest deviation from the ideal slope of 1 , but in terms of stability across all $5 \mathrm{~min}$ intervals the ols-bis performs better. This analysis shows that the extent of underor over-predicting $\mathrm{OH}$ reactivity by short sampling intervals is a matter of how the data are compared to each other.

The same analysis was performed with an extended data set that included 10 times the number of data points of a randomised log-normal distribution to test for any artefacts relating to the limited sample size of the PTR-ToF-MS data. No appreciable difference was obtained when compared to the smaller data set. Hence, we conclude that the observed bias to an overestimation for the bivariate fits and an underestimation for the ols-bis regression on average is real and not an artefact caused by computing a shorter time series. 


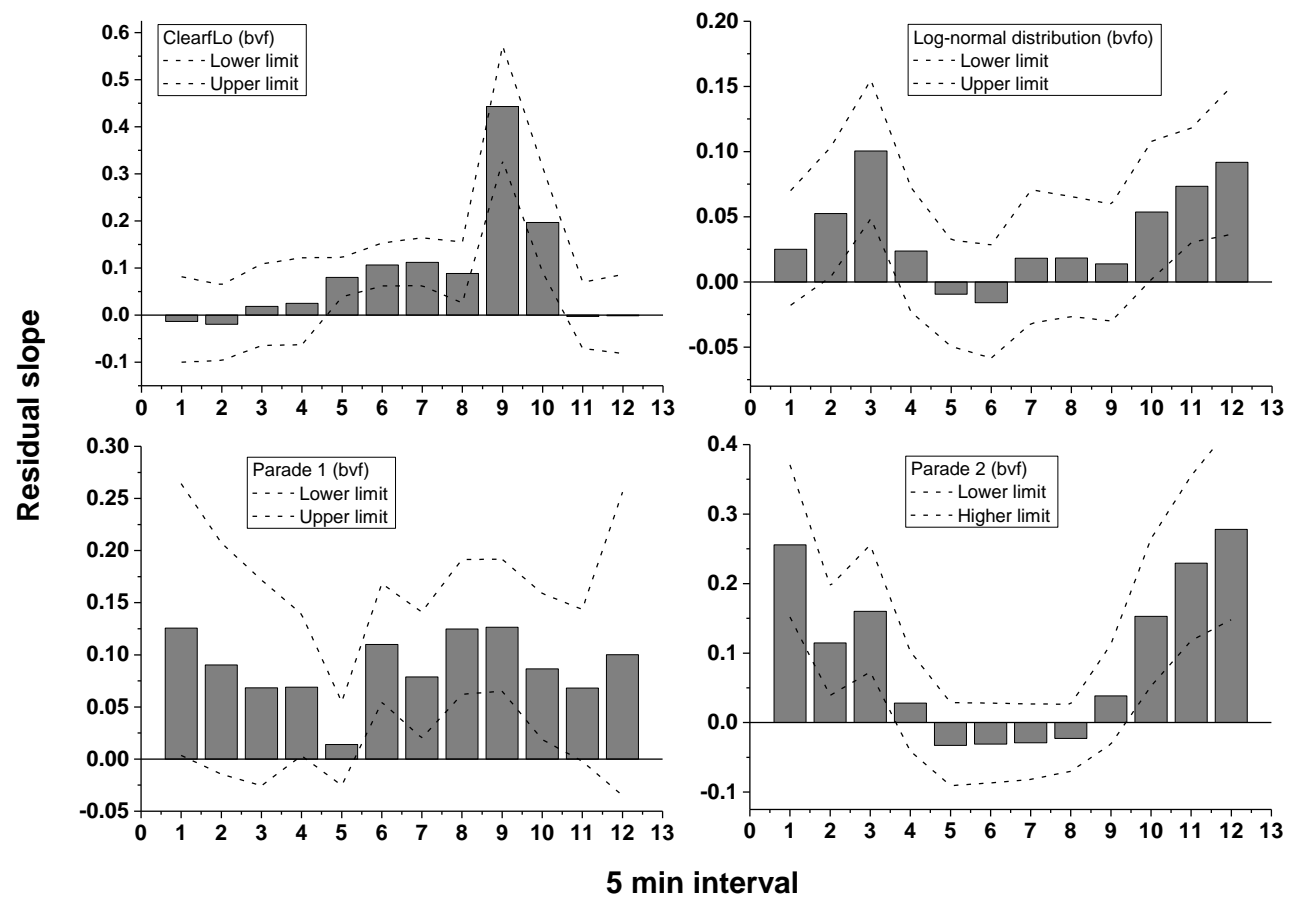

Figure 9. Residual slopes of the correlation of all 5 min means to the hourly mean.

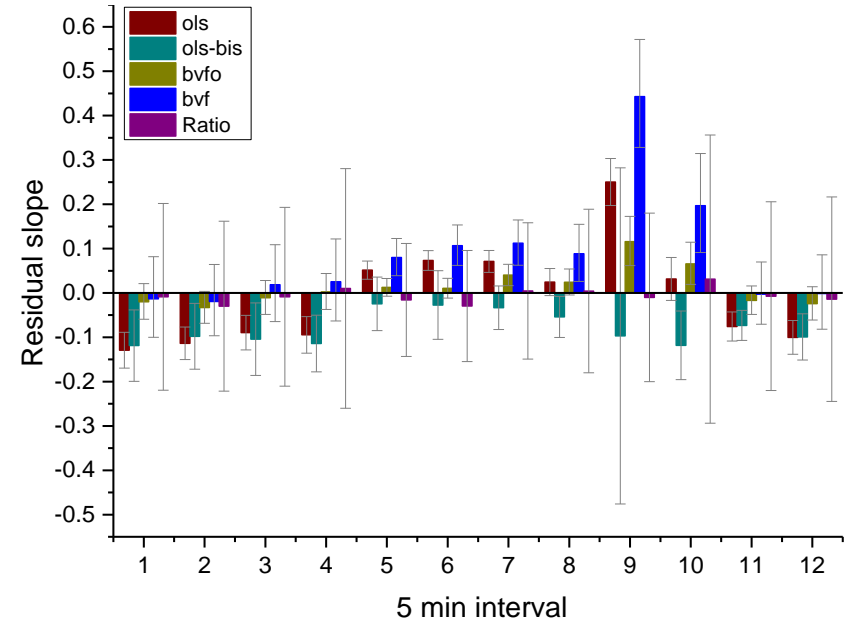

Figure 10. Residual slopes from different linear regression methods and the mean residual ratio for all 5 min intervals. Error bars depict the standard error of the slope for the ols fit, the square root of the variance for the ols-bis, and the lower and upper limit for the bvfo and bvf fits and the standard deviation of the ratios.

\subsection{At what sampling interval can the hourly mean be represented with a smaller subsample?}

The question being further investigated here is: how many data points are needed to calculate an average value that represents the hourly mean within its standard deviation? The ClearfLo data set of $\mathrm{OH}$ reactivity, based on acetone, toluene and xylene, was used to calculate 60 min means of consecutive 1 min data. Small gaps in the time series were skipped such that 60 contiguous data points were computed. However, data was discarded if it included larger gaps, e.g. $1 \mathrm{~h}$ or more. The set of 60 data points was further subdivided into smaller intervals to calculate means of $\mathrm{OH}$ reactivity $R_{\mathrm{PTR}, \mathrm{CL}}^{\mathrm{VOC},<0}$ of $2,3,5,10,15,20$ and $30 \mathrm{~min}$. Residual reactivities for these averages were calculated by subtracting the hourly mean $R_{\mathrm{PTR}, \mathrm{CL}}^{\mathrm{VOC}, \mathrm{C}}$ before being plotted against the number of data points $n$, which in this case corresponds to minutes (Fig. 11). Corresponding standard deviations were calculated for each $60 \mathrm{~min}$ mean, but only the minimum and maximum values are plotted in Fig. 11 (dashed and solid grey lines, respectively). Additionally, two models are plotted, describing the course of the functions $f_{1}(1 / n)$ (light blue) and $f_{2}(1 / \sqrt{n})$ (dark blue) starting at the maximum and minimum value (both marked as red dots). The positive range of residual $\mathrm{OH}$ reactivity is much wider than the negative range and is capped by the $1 / \sqrt{n}$ function. The negative values show a slower approach to the mean. The $20 \mathrm{~min}$ averages all lie within the maximum standard deviation, but even when averaging over $30 \mathrm{~min}$, the range is much wider than the minimum standard deviation of $\mathrm{OH}$ reactivity.

The 2, 3, 5, 10, 20 and 30 min averages are now compared directly to their hourly mean and standard deviation to summarise the findings from Fig. 11. As can be seen in Table 9 at 20 min, $2.78 \%$ of the ClearfLo data still exceed their hourly mean. At $30 \mathrm{~min}$ all data lie within the range of the standard deviation. Therefore, a sampling time greater than $20 \mathrm{~min}$ 


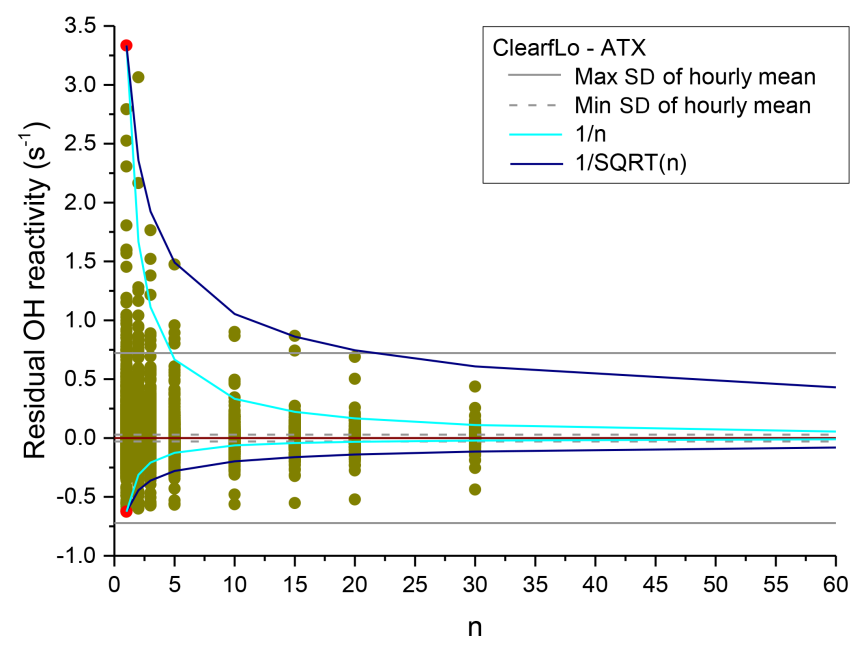

Figure 11. Dependency of the deviation in $\mathrm{OH}$ reactivity from the hourly mean on the number of data points for the entire ClearfLo data set.

would be required to represent the hourly mean. The random data reach a comparable level of data exceeding the hourly mean by $2.80 \%$ for averaging over 5 min only. Here, sampling for only 10 min would be sufficient for representing an hour's worth of data. The required sampling times mentioned here correspond to the VOC variability in the analysed data sets. Likewise, longer sampling times could be necessary for representing hourly $\mathrm{OH}$ reactivity in other environments such as measurements closer to industrial sources. For example, Gilman et al. (2009) have shown that a much broader range of $\mathrm{OH}$ reactivity of VOCs with a high degree of variability can be found in the proximity of heavily industrialised areas like the Houston and Galveston Bay area in Texas, USA.

\subsection{Effect of different VOC classes on $\mathrm{OH}$ reactivity}

Many different atmospheric VOCs have been identified (Goldstein and Galbally, 2007), all of which contribute to $\mathrm{OH}$ reactivity. Based on their chemical characteristics they are often divided into different classes. In order to identify how the variation in individual components contributes to the observed deviation of $R_{\mathrm{PTR}}^{\mathrm{VOC}, 5}$ from $R_{\mathrm{PTR}}^{\mathrm{VOC}, 60}$, correlations between $5 \mathrm{~min}$ and hourly mean reactivities were analysed for different VOC classes separately. The results are shown in Fig. 12 for ClearfLo (blue area) and PARADE (grey and green areas), where OVOC contains the data from acetone for ClearfLo $\left(R_{\mathrm{PTR}, \mathrm{OL}}^{\mathrm{OVOC}}\right)$ and acetone and methanol for PARADE $\left(R_{\mathrm{PTR}, \mathrm{PAR}}^{\mathrm{OVOC}}\right)$. The aromatics are calculated from toluene and xylene and BVOC refers to the sum of the monoterpenes, which were only available for PARADE. Again, a greater deviation from 1 is observed for the PARADE data. The OVOCs show no significant deviation from 1 for both campaigns, and while the aromatics are close to 1 for ClearfLo, they show a significantly different value for PARADE with a

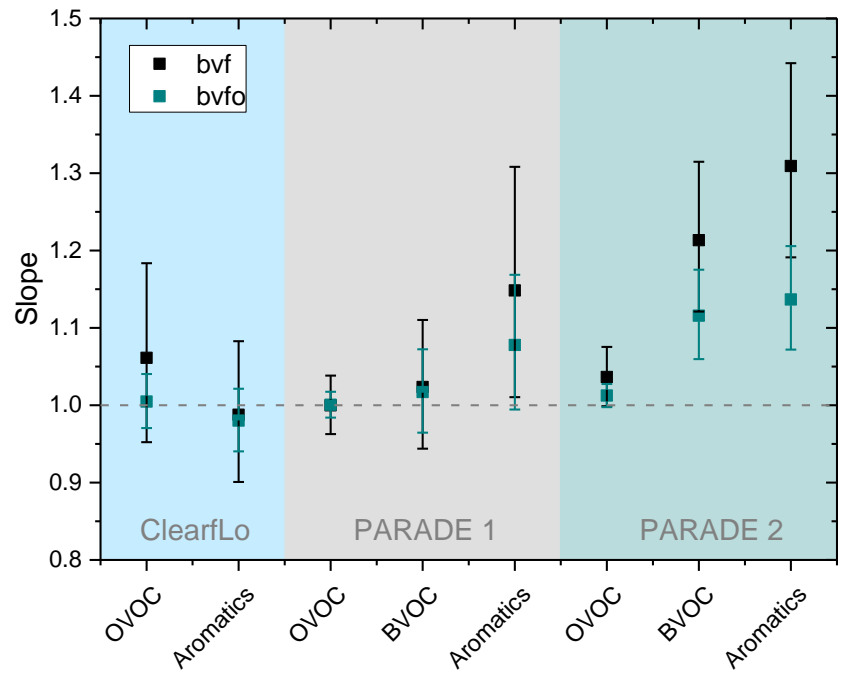

Figure 12. Bivariate fit results between $5 \mathrm{~min}$ averaged to $60 \mathrm{~min}$ averaged reactivity. Slopes are plotted for ClearfLo (blue shaded area, left) and PARADE (Period 1 - grey shaded; Period 2 - green shaded, right). Correlations were analysed separately for OVOCs (acetone for ClearfLo and acetone and methanol for PARADE), BVOCs (monoterpenes) and aromatic compounds (toluene and xylene). The error bars indicate lower and upper limits of the fitted slopes.

deviation of up to $31 \%$. Finally, BVOCs deviate from a perfect correlation by $21 \%$ for the second period of PARADE.

These results are in line with observations from Williams et al. (2000), who investigated the variability-lifetime relationship of VOCs measured in an unpolluted region of Surinam based on the standard deviation of the natural logarithm of their concentration. They found a higher variability for toluene compared to acetone and methanol. Compounds with a lifetime below 2 days did not seem to fit into this relationship.

\subsection{Scaling the effect to the share of $\mathrm{OH}$ reactivity of VOCs during ClearfLo}

The observed deviations of the slopes from the ideal slope of 1 in Fig. 12 for ClearfLo were scaled by their share to determine the overall effect on total OH reactivity of VOC $R_{\mathrm{CL}}^{\mathrm{TVOC}}$. Data from the same week as the PTR-ToF-MS data were used to calculate the influence of $\mathrm{VOC}$ speciation on $\mathrm{OH}$ reactivity. Over the period of 1 to 7 February 2012 the total $\mathrm{OH}$ reactivity of these compounds is $R_{\mathrm{GC}, \mathrm{CL}}^{\mathrm{TVOC}}=4.05 \mathrm{~s}^{-1}$. Based on Table 1, OVOCs contribute most to reactivity at $43 \%$, followed by alkenes at $26 \%$ and alkanes at $21 \%$ of $R_{\mathrm{GC}, \mathrm{CL}}^{\mathrm{TVOC}}$. The aromatic compounds have a share of $6 \%$, and dienes, including isoprene, account for $3 \%$. Finally, the contribution of the only measured alkyne is less than $1 \%$.

The extent of which different VOC classes' variability effects $R_{\mathrm{GC}, \mathrm{TL}}^{\mathrm{TVOC}}$ was calculated by weighting the deviation de- 
Table 9. Comparison to the hourly averages and their standard deviation for ClearfLo and a data set of log-normal distributed randomised numbers. Listed are the number and the percentage of data that exceed the SD of the hourly mean for different $n$. $n$ refers to the number of minutes that were averaged in each case.

\begin{tabular}{rrrrrrr}
\hline & \multicolumn{5}{c}{ ClearfLo } & \multicolumn{3}{c}{ Randomised data set } \\
\cline { 2 - 6 }$n$ & No. data & No. data $>$ SD & \% of data $>$ SD & No. data & No. data $>$ SD & \% of data $>$ SD \\
\hline 2 & 3960 & 838 & 21.16 & 4020 & 534 & 13.28 \\
3 & 2640 & 457 & 17.31 & 2680 & 199 & 7.43 \\
5 & 1584 & 225 & 14.20 & 1608 & 45 & 2.80 \\
10 & 792 & 80 & 10.10 & 804 & 0 & 0 \\
15 & 528 & 38 & 7.20 & 536 & 0 & 0 \\
20 & 396 & 11 & 2.78 & 402 & 0 & 0 \\
30 & 264 & 0 & 0 & 268 & 0 & 0 \\
\hline
\end{tabular}

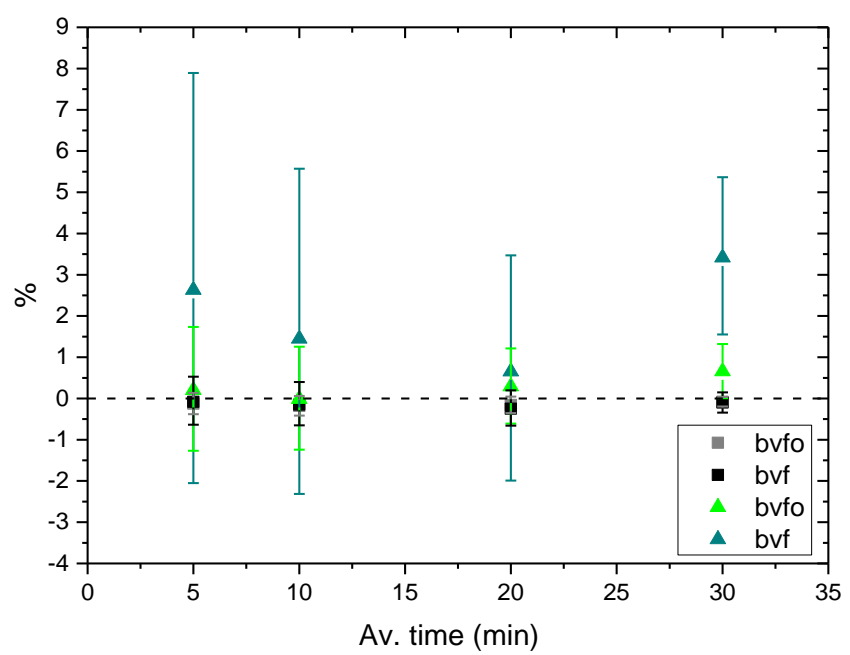

Figure 13. Percentage deviation in $\mathrm{OH}$ reactivity for different sampling intervals owing to VOC variability for the ClearfLo data. Results are plotted separately for aromatic compounds (black and grey squares) and OVOCs (green and teal triangles) for both bivariate fits without (bvfo) and with an intercept (bvf). The deviations are based on the share of the VOC's class to total OH reactivity for each investigated averaging interval. The error bars indicate lower and upper limits of the fitted slopes.

rived from the correlations for the different classes (i.e. the deviation of the slope between $R_{\mathrm{PTR}, \mathrm{CL}}^{\text {class } 5}$ and $R_{\mathrm{PTR}, \mathrm{CL}}^{\text {class, } 60}$ from 1) by the proportion that each class contributes to the total reactivity (calculated from Table 1). Here, it is assumed that deviations derived from measurements of only a few compounds is representative of each class of VOCs under study.

Based on Fig. 13, 5 min averages over-predict $\mathrm{OH}$ reactivity by up to $2.6 \%$ due to variability in OVOC concentrations. This value decreases for increasing averaging time but shows a maximum of $3.4 \%$ for the 30 min mean. There is no significant contribution of the aromatic compounds to a deviation from the hourly mean $\mathrm{OH}$ reactivity for any averaging interval.
A similar behaviour could be expected for other classes of VOCs such as the alkenes and alkanes, the second and third most important classes in Table 1. However, this could not be tested in the present study using PTR-ToF-MS data. However, this study shows how the effect of using short sampling intervals could account for a missing or over-predicted $\mathrm{OH}$ reactivity in the range of $10 \%$ or more.

Lidster et al. (2014) investigated the potential increase in $\mathrm{OH}$ reactivity owing to higher substituted aromatic compounds, which are normally not measured in field campaigns. They state that they can contribute to up to $0.9 \mathrm{~s}^{-1}$ in $\mathrm{OH}$ reactivity. This would increase the share of aromatic compounds by more than a factor of 3 ; however, based on the results in Fig. 13, the effect on $\mathrm{OH}$ reactivity would still be in the range of less than $1 \%$, while the contribution of the OVOCs would only be altered slightly.

\section{Conclusions}

The effect of using short sampling intervals for VOC measurements on resulting $\mathrm{OH}$ reactivity was investigated using two different monitoring campaigns as case studies. $\mathrm{OH}$ reactivity was found to be both under- and over-predicted due to missing variability in VOC data. The divergence between $\mathrm{OH}$ reactivity calculated from $5 \mathrm{~min}$ sampling intervals and hourly values was found to be around $2-26 \%$ and $0-44 \%$ for the PARADE and CleafLo campaigns, respectively, owing to the variability in the VOC concentrations. These discrepancies may contribute to missing $\mathrm{OH}$ reactivity when compared to direct measurements. Results from the urban and the semirural site show on average similar effects when comparing reactivity averaged over $5 \mathrm{~min}$ intervals to the hourly mean.

Comparison to a randomised data set with a similar distribution as the CleafLo data showed that the variability in the VOC concentrations with time is the main reason for deviating results from shorter sampling intervals. For the randomised data a sampling time of less then $10 \mathrm{~min}$ is sufficient so that all data points are within the range of the hourly stan- 
dard deviation, while for the ClearfLo data it takes more than $20 \mathrm{~min}$.

The effect of short sampling times of VOC concentrations on calculated $\mathrm{OH}$ reactivity is differently pronounced for each VOC class. When comparing $\mathrm{OH}$ reactivity calculated from VOCs sampled over a $5 \mathrm{~min}$ period to the hourly mean, a larger divergence was found for the OVOCs than aromatic compounds during ClearfLo. The opposite trend was observed for the PARADE campaign, while the effect of OVOCs is almost negligible. Biogenic VOCs, with the monoterpenes as representatives, were added for analysis. They show a similar behaviour to the OVOCs, but with a slightly greater divergence.

The bigger proportion of measured OVOCs, compared to the aromatic compounds, at the urban site during ClearfLo contributes to a higher deviation in calculated $\mathrm{OH}$ reactivity when using short sampling intervals. Taking the results from Lidster et al. (2014) into account, the effect of aromatic VOCs increases but is still small.

Acknowledgements. The authors would like to thank Lisa Whalley from the University of Leeds for useful comments on the manuscript. We acknowledge funding from the Natural Environment Research Council through NE/H003207/1 for ClearfLo and EU PEGASOS. We would like to thank all participants and supporters of the PARADE field campaign 2011 at Taunus Observatory for organisation, logistical support and a nice field campaign.

Edited by: F. Keutsch

\section{References}

Atkinson, R. and Arey, J.: Atmospheric degradation of volatile organic compounds, Chem. Rev., 103, 4605-4638, 2003.

Barber, S., Blake, R. S., White, I. R., Monks, P. S., Reich, F., Mullock, S., and Ellis, A. M.: Increased sensitivity in proton transfer reaction mass spectrometry by incorporation of a radio frequency ion funnel, Anal. Chem., 84, 5387-5391, 2012.

Bohnenstengel, S. I., Belcher, S. E., Aiken, A., Allan, J. D., Allen, G., Bacak, A., Bannan, T. J., Barlow, J. F., Beddows, D. C. S., Bloss, W. J., Booth, A. M., Chemel, C., Coceal, O., Di Marco, C. F., Dubey, M. K., Faloon, K. H., Fleming, Z. L., Furger, M., Gietl, J. K., Graves, R. R., Green, D. C., Grimmond, C. S. B., Halios, C. H., Hamilton, J. F., Harrison, R. M., Heal, M. R., Heard, D. E., Helfter, C., Herndon, S. C., Holmes, R. E., Hopkins, J. R., Jones, A. M., Kelly, F. J., Kotthaus, S., Langford, B., Lee, J. D., Leigh, R. J., Lewis, A. C., Lidster, R. T., Lopez-Hilfiker, F. D., McQuaid, J. B., Mohr, C., Monks, P. S., Nemitz, E., Ng, N. L., Percival, C. J., Prevot, A. S. H., Ricketts, H. M. A., Sokhi, R., Stone, D., Thornton, J. A., Tremper, A. H., Valach, A. C., Visser, S., Whalley, L. K., Williams, L. R., Xu, L., Young, D. E., and Zotter, P.: Meteorology, Air Quality, and Health in London: The ClearfLo Project, B. Am. Meteorol. Soc., 96, 779-804, 2015.

Bonn, B., Bourtsoukidis, E., Sun, T. S., Bingemer, H., Rondo, L., Javed, U., Li, J., Axinte, R., Li, X., Brauers, T., Sonderfeld, H., Koppmann, R., Sogachev, A., Jacobi, S., and Spracklen, D. V.:
The link between atmospheric radicals and newly formed particles at a spruce forest site in Germany, Atmos. Chem. Phys., 14, 10823-10843, doi:10.5194/acp-14-10823-2014, 2014.

Cantrell, C. A.: Technical Note: Review of methods for linear leastsquares fitting of data and application to atmospheric chemistry problems, Atmos. Chem. Phys., 8, 5477-5487, doi:10.5194/acp8-5477-2008, 2008.

Chung, M. Y., Maris, C., Krischke, U., Meller, R., and Paulson, S. E.: An investigation of the relationship between total nonmethane organic carbon and the sum of speciated hydrocarbons and carbonyls measured by standard GC/FID: measurements in the Los Angeles air basin, Atmos. Environ., 37, Supplement 2, 159-170, 2003.

Crowley, J. N., Schuster, G., Pouvesle, N., Parchatka, U., Fischer, H., Bonn, B., Bingemer, H., and Lelieveld, J.: Nocturnal nitrogen oxides at a rural mountain-site in south-western Germany, Atmos. Chem. Phys., 10, 2795-2812, doi:10.5194/acp-10-27952010, 2010.

Di Carlo, P., Brune, W. H., Martinez, M., Harder, H., Lesher, R., Ren, X., Thornberry, T., Carroll, M. A., Young, V., and Shepson, P. B.: Missing $\mathrm{OH}$ reactivity in a forest: Evidence for unknown reactive biogenic VOCs, Science, 304, 722-725, 2004.

Dolgorouky, C., Gros, V., Sarda-Esteve, R., Sinha, V., Williams, J., Marchand, N., Sauvage, S., Poulain, L., Sciare, J., and Bonsang, B.: Total OH reactivity measurements in Paris during the 2010 MEGAPOLI winter campaign, Atmos. Chem. Phys., 12, 95939612, doi:10.5194/acp-12-9593-2012, 2012.

Edwards, P. M., Evans, M. J., Furneaux, K. L., Hopkins, J., Ingham, T., Jones, C., Lee, J. D., Lewis, A. C., Moller, S. J., Stone, D., Whalley, L. K., and Heard, D. E.: OH reactivity in a South East Asian tropical rainforest during the Oxidant and Particle Photochemical Processes (OP3) project, Atmos. Chem. Phys., 13, 9497-9514, doi:10.5194/acp-13-9497-2013, 2013.

Gilman, J. B., Kuster, W. C., Goldan, P. D., Herndon, S. C., Zahniser, M. S., Tucker, S. C., Brewer, W. A., Lerner, B. M., Williams, E. J., and Harley, R. A.: Measurements of volatile organic compounds during the 2006 TexAQS/GoMACCS campaign: Industrial influences, regional characteristics, and diurnal dependencies of the $\mathrm{OH}$ reactivity, J. Geophys. Res.-Atmos., 114, D00F06, doi:10.1029/2008JD011525, 2009.

Goldstein, A. H. and Galbally, I. E.: Known and unexplored organic constituents in the earth's atmosphere, Environ. Sci. Technol., 41, 1514-1521, 2007.

Hansen, R. F., Griffith, S. M., Dusanter, S., Rickly, P. S., Stevens, P. S., Bertman, S. B., Carroll, M. A., Erickson, M. H., Flynn, J. H., Grossberg, N., Jobson, B. T., Lefer, B. L., and Wallace, H. W.: Measurements of total hydroxyl radical reactivity during CABINEX 2009 - Part 1: field measurements, Atmos. Chem. Phys., 14, 2923-2937, doi:10.5194/acp-14-2923-2014, 2014.

Hofzumahaus, A., Rohrer, F., Lu, K., Bohn, B., Brauers, T., Chang, C.-C., Fuchs, H., Holland, F., Kita, K., and Kondo, Y.: Amplified trace gas removal in the troposphere, Science, 324, 1702-1704, 2009.

Hopkins, J. R., Lewis, A. C., and Read, K. A.: A two-column method for long-term monitoring of non-methane hydrocarbons (NMHCs) and oxygenated volatile organic compounds (oVOCs), J. Environ. Monitor. 5, 8-13, 2003.

Ingham, T., Goddard, A., Whalley, L. K., Furneaux, K. L., Edwards, P. M., Seal, C. P., Self, D. E., Johnson, G. P., Read, K. A., Lee, 
J. D., and Heard, D. E.: A flow-tube based laser-induced fluorescence instrument to measure $\mathrm{OH}$ reactivity in the troposphere, Atmos. Meas. Tech., 2, 465-477, doi:10.5194/amt-2-465-2009, 2009.

Isobe, T., Feigelson, E. D., Akritas, M. G., and Babu, G. J.: Linear regression in astronomy, Astrophys. J., 364, 104-113, 1990.

Jordan, A., Haidacher, S., Hanel, G., Hartungen, E., Märk, L., Seehauser, H., Schottkowsky, R., Sulzer, P., and Märk, T.: A high resolution and high sensitivity proton-transfer-reaction time-offlight mass spectrometer (PTR-TOF-MS), Int. J. Mass Spectrom., 286, 122-128, 2009.

Kim, S., Guenther, A., Karl, T., and Greenberg, J.: Contributions of primary and secondary biogenic VOC tototal $\mathrm{OH}$ reactivity during the CABINEX (Community Atmosphere-Biosphere INteractions Experiments)-09 field campaign, Atmos. Chem. Phys., 11, 8613-8623, doi:10.5194/acp-11-8613-2011, 2011.

Kovacs, T. A. and Brune, W. H.: Total OH loss rate measurement, J. Atmos. Chem., 39, 105-122, 2001.

Kovacs, T. A., Brune, W., Harder, H., Martinez, M., Simpas, J., Frost, G., Williams, E., Jobson, T., Stroud, C., and Young, V.: Direct measurements of urban $\mathrm{OH}$ reactivity during Nashville SOS in summer 1999, J. Environ. Monitor., 5, 68-74, 2003.

Lewis, A. C., Carslaw, N., Marriott, P. J., Kinghorn, R. M., Morrison, P., Lee, A. L., Bartle, K. D., and Pilling, M. J.: A larger pool of ozone-forming carbon compounds in urban atmospheres, Nature, 405, 778-781, 2000.

Lidster, R. T., Hamilton, J. F., Lee, J. D., Lewis, A. C., Hopkins, J. R., Punjabi, S., Rickard, A. R., and Young, J. C.: The impact of monoaromatic hydrocarbons on $\mathrm{OH}$ reactivity in the coastal UK boundary layer and free troposphere, Atmos. Chem. Phys., 14, 6677-6693, doi:10.5194/acp-14-6677-2014, 2014.

Limpert, E., Stahel, W. A., and Abbt, M.: Log-normal Distributions across the Sciences: Keys and Clues On the charms of statistics, and how mechanical models resembling gambling machines offer a link to a handy way to characterize log-normal distributions, which can provide deeper insight into variability and probability - normal or log-normal: That is the question, BioScience, 51, 341-352, 2001.

Lou, S., Holland, F., Rohrer, F., Lu, K., Bohn, B., Brauers, T., Chang, C. C., Fuchs, H., Häseler, R., Kita, K., Kondo, Y., Li, X., Shao, M., Zeng, L., Wahner, A., Zhang, Y., Wang, W., and Hofzumahaus, A.: Atmospheric $\mathrm{OH}$ reactivities in the Pearl River Delta - China in summer 2006: measurement and model results, Atmos. Chem. Phys., 10, 11243-11260, doi:10.5194/acp-10-11243-2010, 2010.

Mao, J., Ren, X., Brune, W. H., Olson, J. R., Crawford, J. H., Fried, A., Huey, L. G., Cohen, R. C., Heikes, B., Singh, H. B., Blake, D. R., Sachse, G. W., Diskin, G. S., Hall, S. R., and Shetter, R. E.: Airborne measurement of $\mathrm{OH}$ reactivity during INTEX-B, Atmos. Chem. Phys., 9, 163-173, doi:10.5194/acp-9-163-2009, 2009.

Mogensen, D., Smolander, S., Sogachev, A., Zhou, L., Sinha, V., Guenther, A., Williams, J., Nieminen, T., Kajos, M. K., Rinne, J., Kulmala, M., and Boy, M.: Modelling atmospheric OH-reactivity in a boreal forest ecosystem, Atmos. Chem. Phys., 11, 97099719, doi:10.5194/acp-11-9709-2011, 2011.

Monks, P. S., Granier, C., Fuzzi, S., Stohl, A., Williams, M. L., Akimoto, H., Amann, M., Baklanov, A., Baltensperger, U., Bey, I., Blake, N., Blake, R. S., Carslaw, K., Cooper, O. R., Dentener,
F., Fowler, D., Fragkou, E., Frost, G. J., Generoso, S., Ginoux, P., Grewe, V., Guenther, A., Hansson, H. C., Henne, S., Hjorth, J., Hofzumahaus, A., Huntrieser, H., Isaksen, I. S. A., Jenkin, M. E., Kaiser, J., Kanakidou, M., Klimont, Z., Kulmala, M., Laj, P., Lawrence, M. G., Lee, J. D., Liousse, C., Maione, M., McFiggans, G., Metzger, A., Mieville, A., Moussiopoulos, N., Orlando, J. J., O’Dowd, C. D., Palmer, P. I., Parrish, D. D., Petzold, A., Platt, U., Pöschl, U., Prévôt, A. S. H., Reeves, C. E., Reimann, S., Rudich, Y., Sellegri, K., Steinbrecher, R., Simpson, D., ten Brink, H., Theloke, J., van der Werf, G. R., Vautard, R., Vestreng, V., Vlachokostas, C., and von Glasow, R.: Atmospheric composition change - global and regional air quality, Atmos. Environ., 43, 5268-5350, 2009.

Nölscher, A. C., Williams, J., Sinha, V., Custer, T., Song, W., Johnson, A. M., Axinte, R., Bozem, H., Fischer, H., Pouvesle, N., Phillips, G., Crowley, J. N., Rantala, P., Rinne, J., Kulmala, M., Gonzales, D., Valverde-Canossa, J., Vogel, A., Hoffmann, T., Ouwersloot, H. G., Vilà-Guerau de Arellano, J., and Lelieveld, J.: Summertime total $\mathrm{OH}$ reactivity measurements from boreal forest during HUMPPA-COPEC 2010, Atmos. Chem. Phys., 12, 8257-8270, doi:10.5194/acp-12-8257-2012, 2012a.

Nölscher, A. C., Sinha, V., Bockisch, S., Klüpfel, T., and Williams, J.: Total $\mathrm{OH}$ reactivity measurements using a new fast Gas Chromatographic Photo-Ionization Detector (GC-PID), Atmos. Meas. Tech., 5, 2981-2992, doi:10.5194/amt-5-2981-2012, 2012 b.

Nölscher, A. C., Bourtsoukidis, E., Bonn, B., Kesselmeier, J., Lelieveld, J., and Williams, J.: Seasonal measurements of total $\mathrm{OH}$ reactivity emission rates from Norway spruce in 2011, Biogeosciences, 10, 4241-4257, doi:10.5194/bg-10-4241-2013, 2013.

Phillips, G., Tang, M., Thieser, J., Brickwedde, B., Schuster, G., Bohn, B., Lelieveld, J., and Crowley, J.: Significant concentrations of nitryl chloride observed in rural continental Europe associated with the influence of sea salt chloride and anthropogenic emissions, Geophys. Res. Lett., 39, L10811, doi:10.1029/2012GL051912, 2012.

Ren, X., Harder, H., Martinez, M., Lesher, R. L., Oliger, A., Shirley, T., Adams, J., Simpas, J. B., and Brune, W. H.: HO_x concentrations and $\mathrm{OH}$ reactivity observations in New York City during PMTACS-NY2001, Atmos. Environ., 37, 3627-3637, 2003a.

Ren, X., Harder, H., Martinez, M., Lesher, R. L., Oliger, A., Simpas, J. B., Brune, W. H., Schwab, J. J., Demerjian, K. L., and He, Y.: OH and HO_2 Chemistry in the urban atmosphere of New York City, Atmos. Environ., 37, 3639-3651, 2003b.

Ren, X., Brune, W. H., Oliger, A., Metcalf, A. R., Simpas, J. B., Shirley, T., Schwab, J. J., Bai, C., Roychowdhury, U., and $\mathrm{Li}$, Y.: $\mathrm{OH}, \mathrm{HO}_{2}$, and $\mathrm{OH}$ reactivity during the PMTACSNY Whiteface Mountain 2002 campaign: Observations and model comparison, J. Geophys. Res.-Atmos., 111, D10S03, doi:10.1029/2005JD006126, 2006.

Sadanaga, Y., Yoshino, A., Watanabe, K., Yoshioka, A., Wakazono, Y., Kanaya, Y., and Kajii, Y.: Development of a measurement system of $\mathrm{OH}$ reactivity in the atmosphere by using a laserinduced pump and probe technique, Rev. Sci. Instrum., 75, 26482655, 2004.

Sadanaga, Y., Yoshino, A., Kato, S., and Kajii, Y.: Measurements of $\mathrm{OH}$ reactivity and photochemical ozone production in the urban atmosphere, Environ. Sci. Technol., 39, 8847-8852, 2005. 
Shirley, T. R., Brune, W. H., Ren, X., Mao, J., Lesher, R., Cardenas, B., Volkamer, R., Molina, L. T., Molina, M. J., Lamb, B., Velasco, E., Jobson, T., and Alexander, M.: Atmospheric oxidation in the Mexico City Metropolitan Area (MCMA) during April 2003, Atmos. Chem. Phys., 6, 2753-2765, doi:10.5194/acp-62753-2006, 2006.

Sinha, V., Williams, J., Crowley, J. N., and Lelieveld, J.: The Comparative Reactivity Method - a new tool to measure total $\mathrm{OH}$ Reactivity in ambient air, Atmos. Chem. Phys., 8, 2213-2227, doi:10.5194/acp-8-2213-2008, 2008.

Sinha, V., Williams, J., Lelieveld, J., Ruuskanen, T., Kajos, M., Patokoski, J., Hellen, H., Hakola, H., Mogensen, D., and Boy, M.: $\mathrm{OH}$ reactivity measurements within a boreal forest: evidence for unknown reactive emissions, Environ. Sci. Technol., 44, 66146620, 2010.

Thalman, R., Baeza-Romero, M. T., Ball, S. M., Borrás, E., Daniels, M. J. S., Goodall, I. C. A., Henry, S. B., Karl, T., Keutsch, F. N., Kim, S., Mak, J., Monks, P. S., Mu 'noz, A., Orlando, J., Peppe, S., Rickard, A. R., Ródenas, M., Sánchez, P., Seco, R., Su, L., Tyndall, G., Vázquez, M., Vera, T., Waxman, E., and Volkamer, R.: Instrument intercomparison of glyoxal, methyl glyoxal and $\mathrm{NO}_{2}$ under simulated atmospheric conditions, Atmos. Meas. Tech., 8, 1835-1862, doi:10.5194/amt-8-1835-2015, 2015.
Warton, D. I., Wright, I. J., Falster, D. S., and Westoby, M.: Bivariate line-fitting methods for allometry, Biol. Rev., 81, 259-291, 2006.

Whalley, L. K., Edwards, P. M., Furneaux, K. L., Goddard, A., Ingham, T., Evans, M. J., Stone, D., Hopkins, J. R., Jones, C. E., Karunaharan, A., Lee, J. D., Lewis, A. C., Monks, P. S., Moller, S. J., and Heard, D. E.: Quantifying the magnitude of a missing hydroxyl radical source in a tropical rainforest, Atmos. Chem. Phys., 11, 7223-7233, doi:10.5194/acp-11-7223-2011, 2011.

Williams, J., Fischer, H., Harris, G., Crutzen, P., Hoor, P., Hansel, A., Holzinger, R., Warneke, C., Lindinger, W., and Scheeren, B.: Variability-lifetime relationship for organic trace gases: A novel aid to compound identification and estimation of HO concentrations, J. Geophys. Res.-Atmos., 105, 20473-20486, 2000.

Yoshino, A., Sadanaga, Y., Watanabe, K., Kato, S., Miyakawa, Y., Matsumoto, J., and Kajii, Y.: Measurement of total $\mathrm{OH}$ reactivity by laser-induced pump and probe technique - Comprehensive observations in the urban atmosphere of Tokyo, Atmos. Environ., 40, 7869-7881, 2006. 